\title{
Peripheral Nerve Injury Induces Schwann Cells to Express Two Macrophage Phenotypes: Phagocytosis and the Galactose-Specific Lectin MAC-2
}

\author{
Fanny Reichert, Ann Saada, and Shlomo Rotshenker \\ Department of Anatomy and Embryology, Hebrew University, Hadassah Medical School, Jerusalem, Israel
}

In $\mathbf{N}$ mice, peripheral nerve injury is followed by the normal rapid progression of Wallerian degeneration: Schwann cells proliferate and lose their myelin, which is phagocytized and metabolized by blood-borne macrophages. The role of Schwann cells in myelin phagocytosis is debated. Additionally, the molecular mechanisms underlying myelin phagocytosis by the two cell types are not well understood. To elucidate the role of Schwann cells as phagocytes we studied, electron microscopically, in vivo and in vitro degenerating, frozen, and neuroma nerve segments. The major cell types composing these tissues differed: Schwann and macrophages in in vivo degenerating; Schwann in in vitro degenerating; macrophages in frozen; Schwann, macrophages, and fibroblasts in neuroma nerve segments. Both macrophages and Schwann cells phagocytized myelin. We further studied, by immunocytochemistry and immunoblot analysis, the expression of molecules that are characteristically displayed by inflammatory and mature murine macrophages: MAC-1 (the C3b complement receptor), MAC-2 (a galactose-specific lectin), the Fc receptor, and the F4/80 antigen. All were detected in the macrophage-rich, in vivo degenerating, frozen, and neuroma nerve segments. Surprisingly, MAC-2 was also expressed in the macrophage-scarce, Schwann-rich, in vitro degenerating nerve. Immunocytochemistry and immunoblot analysis of isolated non-neuronal cells revealed that both macrophages and Schwann cells displayed MAC-2 on their surface and in their cytoplasm. Morphometry unveiled that galactose and lactose specifically inhibited myelin phagocytosis, as predicted if MAC-2 was mediating myelin phagocytosis by lectinophagocytosis (lectin-mediated phagocytosis). The role of MAC-2 in mediating myelin phagocytosis was further supported by two observations made in $W$ mice that display very slow progression of Wallerian degeneration. First, the failure to degenerate in vivo was associated with deficient MAC-2 production. Second, degeneration that occurred in vitro was associated with MAC-2 production. Furthermore, a strong positive correlation between levels of MAC-2 expression and the extent of myelin destruction by phagocytosis was observed over a wide range of values.

\footnotetext{
Received Aug. 18, 1993; revised Oct. 25, 1993; accepted Nov. 17, 1993.

This study was supported by grants from the Bernardo Schoenfeld family and the Yeshaya Horowitz Association. A.S. was a recipient of a Lady Davies postdoctoral fellowship.

Correspondence should be addressed to Dr. Shlomo Rotshenker, Department of Anatomy and Embryology, Hebrew University, Hadassah Medical School, POB 12272, Jerusalem 91120 , Israel.

Copyright (c) 1994 Society for Neuroscience 0270-6474/94/143231-15\$05.00/0
}

[Key words: Wallerian degeneration, nerve regeneration, Schwann cells, macrophages, myelin, phagocytosis, lectinophagocytosis, galactose-specific lectin MAC-2I

Peripheral nerve injury is followed by Wallerian degeneration of the nerve segment distal to the lesion site and by axonal regeneration at the neuroma nerve segment just proximal to it (e.g., Ramon y Cajal, 1928). Molecular and cellular cvents that take place during the course of Wallerian degeneration turn the degenerating segment into an environment that supports the regeneration of peripheral and central adult neurons (David and Aguayo, 1981; Bedi et al., 1992). Among the identified molecular changes are increases in the production of interleukin-1 activity (Rotshenker et al., 1992), NGF (e.g., Richardson and Ebendal, 1982; Heumann el al., 1987), and apolipoproteins (e.g., Ignatius et al., 1987; Rotshenker et al., 1990; Aamar et al., 1992). Cellular events that characterize Wallerian degeneration are the breakdown of axons, disintegration of myelin sheaths, proliferation of Schwann cells, and the recruitment of macrophages from the circulation. There is a general agreement that macrophages play a major role in the phagocytosis and metabolism of myelin. There is, however, a long-standing debate whether Schwann cells play a similar role. Recent studies reflect this controversy. On the one hand, no phagocytosis of myelin by Schwann cells was detected in mouse and cat peripheral nerves undergoing axonal degeneration in either diffusion chambers (Beuche and Friede, 1984) or tissue culture (Crang and Blakemore, 1986). On the other hand, phagocytosis of myelin by rat Schwann cells was reported during the course of in vivo, Wallerian degeneration (Stoll et al., 1989), and by neonate Schwann cells in culture (Bigbee et al., 1987).

It can be argued that such inconsistencies could arise from using different preparations in different experimental designs. We examined, therefore, electron microscopically, phagocytosis by Schwann cells and macrophages in four different preparations of injured mouse peripheral nerves. First, we studied cultured explants of intact nerves. In-culture, in vitro axonal degeneration takes place in the presence of the "intact nerve non-neuronal cell population" (i.e., Schwann, fibroblasts, and endothelial cells; Thomas, 1963; Schubert and Friede, 1981), from which bloodborne macrophages are excluded. Second, nerve segments undergoing degeneration in vivo, containing the entire array of non-neuronal cells characteristic of Wallerian degeneration: the "intact nerve non-neuronal cell population" joined by macrophages that are recruited from the circulation (e.g., Beuche and Friede, 1984). Third, nerve segments that were first frozen and then returned in situ. In frozen nerves, the "intact nerve nonneuronal cell population" that had been killed by freezing is 
replaced by blood-borne macrophages (Ide et al., 1983). Fourth, neuroma nerve segments, the site where axonal regeneration commences (Ramon y Cajal, 1928).

We used two strains of mice: (1) the $\mathrm{C} 57 / \mathrm{BL} / 6 \mathrm{NHSD}$ normal mouse ( $\mathrm{N}$ mice) that displays the normal rapid progression of Wallerian degeneration; (2) the C57BL/6-WLD/OLA/NHSD mutant mouse ( $W$ mice; formally known as C57BL/Ola) that displays a very slow progression of Wallerian degeneration (Lunn et al., 1989; Perry et al., 1990). Using $N$ mice we observed, electron microscopically, that Schwann cells phagocytized myelin, thus displaying a phenotype characteristic of macrophages. To test the possibility that additional macrophage phenotypes are expressed by Schwann cells we studied, by immunocytochemistry and immunoblot analysis, the expression of molecules that inflammatory and mature murine macrophages characteristically display (e.g., Nibbering et al., 1987; van-Furth, 1988; Papadimitriou and Ashman, 1989): MAC-1 (the C3b compliment receptor), MAC-2 (a galactose-specific lectin), the $F c$ receptor, and the $F 4 / 80$ antigen (a marker of mature macrophages). MAC-1, MAC-2, and the Fc receptor are of particular interest since each can be instrumental in phagocytosis (e.g., Ofek and Sharon, 1988). MAC-1 and the Fc receptor take part in immune-related, opsonin-dependent phagocytosis in which complement and antigens act as opsonins. The galactose-specific lectin MAC-2, we hypothesize, can be instrumental in the nonimmune-form, opsonin-independent phagocytosis: lectinophagocytosis (lectin-mediated phagocytosis). We detected cell surface and cytoplasmatic MAC-2 in Schwann cells and macrophages. We further observed that galactose and lactose specifically inhibited myelin phagocytosis, indicating that MAC-2 was involved in lectinophagocytosis. Nerve injury thus induces Schwann cells to express MAC-2, and is followed by the recruitment of macrophages that also express MAC-2. In turn, MAC-2 enables Schwann cells and macrophages to display lectinophagocytosis of myelin.

The role of MAC-2 in mediating myelin phagocytosis can be tested in $\mathrm{W}$ mice that display a slow progression of Wallerian degeneration in vivo. Retarded Wallerian degeneration has becn attributed to the slow-pace recruitment of macrophages distal to the lesion site (Lunn et al., 1989; Perry et al., 1990). The failure to recruit macrophages provides only a partial explanation for the lack of myelin destruction if it is accepted that Schwann cells and macrophages exercise MAC-2-mediated myelin phagocytosis. Thus, an additional requirement should be fulfilled: W mouse Schwann cells should fail to express MAC-2 in vivo after nerve transection, which indeed was the case. Some extent of myelin destruction occurred during in vitro degeneration of $\mathrm{W}$ mouse nerve explants. As predicted, this event was associated with MAC-2 expression. Furthermore, there was a positive correlation between levels of MAC-2 expression and extent of myelin destruction by phagocytosis over a wide range of values obtained from $\mathrm{N}$ and $\mathrm{W}$ mice.

\section{Materials and Methods}

Animals and surgical procedures. Two strains of mice, 2-4 months old, were used: (1) the C57/BL/6NHSD normal strain (Harlan-SpragueDawley Inc.) that displays a rapid progression of Wallerian degeneration; (2) the C57/BL/6-WLD/OLA/NHSD mutant strain (Harlan, Olac, England) that displays a slow progression of Wallerian degeneration (Lunn et al., 1989). This strain was formally referred to as C57/BL/Ola by the supplier, which has now assigned the new name to it. We shall refer to the two strains as $\mathrm{N}$ and $\mathrm{W}$, respectively. All surgical procedures were performed under anesthesia. The sciatic nerve was transected after leaving the pelvis. Frozen nerve segments were obtained by subjecting $1 \mathrm{~cm}$ nerve segments to three cycles of freeze/thaw in distilled water. Frozen nerves were returned in situ into the donor animals. Nerve explants were obtained by placing $5 \mathrm{~mm}$ nerve segments in Dulbecco's modified Eagle's medium (DMEM), supplemented by $10 \%$ fetal calf serum (FCS) (Beit-Haemek, Israel). Cultures were kept in a humidified incubator, saturated by $5 \% \mathrm{CO}_{2}$ at $37^{\circ} \mathrm{C}$.

Cell dissociation and culture. We adopted the method described by Scarpini et al. (1988), with some modifications. Briefly, nerves were cut into small pieces and incubated for 18-20 hr in DMEM, 1.2 U/ml dispase, $0.05 \%$ collagenase, and $0.1 \%$ hyaluronidase (Signa, St. Louis, MO). To obtain cultures containing mixed cell populations, the washed cell suspension was plated on poly-L-lysine or laminin (Sigma)-coated plastic culture dishes (Nunc). To obtain Schwann cell cultures, cells were plated on plastic dishes for $1 \mathrm{~d}$. Occasionally, this procedure was repeated twice. Then, the nonadherent cells, primarily Schwann, were plated on poly-L-lysine or laminin (Sigma)-coated dishes. In instances where fibroblasts were still present, the cells were exposed for $3 \mathrm{~d}$ to $10^{-5} \mathrm{M}$ cytosine arabinoside (Sigma).

Immunocytochemistry. Peripheral nerves were sectioned $(8 \mu \mathrm{m})$ in a freezing microtome. Sections were blocked in $20 \%$ normal rabbit serum (NRS) for $20 \mathrm{~min}$, exposed for $60 \mathrm{~min}$ to either one of the rat antimouse monoclonal antibodies (mAbs) raised against MAC-1, MAC-2, F4/80 antigen, and the Fc receptor (diluted $1: 5$ in 10\% NRS, 2.5\% BSA), washed in PBS for $30 \mathrm{~min}$, fixed in $1 \%$ neutral formalin in PBS for 5 min, washed in PBS for $10 \mathrm{~min}$, incubated for $60 \mathrm{~min}$ in FITC-conjugated rabbit anti-rat IgG (diluted 1:500 in 10\% NRS, 2.5\% BSA), and finally washed in PBS for $30 \mathrm{~min}$. The entire staining procedure was carried out at room temperature.

Cells were washed in serum-free DMEM, blocked in $20 \%$ NRS in DMEM for $15 \mathrm{~min}$, exposed for $40 \mathrm{~min}$ to either one of the mAbs raised against MAC-1, MAC-2, F4/80 antigen, and Fc receptor (diluted 1:5 in $10 \%$ NRS in DMEM), washed in Ca-Mg PBS, fixed in PLP (McLean and Nakane, 1974) for $15 \mathrm{~min}$, washed in PBS for $20 \mathrm{~min}$, incubated in FITC-conjugated rabbit anti-rat IgG for $30 \mathrm{~min}$, and finally washed in PBS for $30 \mathrm{~min}$. Procedures up to fixation were carried out at $37^{\circ} \mathrm{C}$, and thereafter at room temperature.

To double stain cells for MAC- 2 and S-100, cell cultures were washed in scrum-frec medium, fixed for $15 \mathrm{~min}$ in PLP, washcd in PBS for 20 min, incubated for $10 \mathrm{~min}$ in $0.05 \%$ Triton in PBS, washed in PBS, blocked in $20 \% \mathrm{NGS} / 5 \% \mathrm{BSA}$ for $15 \mathrm{~min}$, incubated for $1 \mathrm{hr}$ at $37^{\circ} \mathrm{C}$ in polyclonal rabbit anti-bovine antibodies raised against $\mathrm{S}-100$ (diluted 1:500-1000 in 10\% NGS, 2.5\% BSA in PBS), washed in PBS, incubated in rhodamine-conjugated goat anti-rabbit IgG for $30 \mathrm{~min}$ (diluted 1:500 in $10 \% \mathrm{NGS}, 2.5 \% \mathrm{BSA}$ in PBS), and washed in PBS. Cells were then exposed to anti-MAC-2 for $30 \mathrm{~min}$ (dilution of $1: 200$ in 10\% NRS, $2.5 \%$ BSA in PBS), washed in PBS, incubated in FITC-conjugated rabbit anti-rat IgG (diluted $1: 1000$ in 10\% NRS, $2.5 \%$ BSA in PBS), and finally washed in PBS.

The $\mathrm{mAbs}$ raised against $\mathrm{MAC}-1, \mathrm{F4} / 80$ antigen, and $\mathrm{Fc}$ receptor were obtained from Serotec, the hybridoma cell line M3/38 producing anti-MAC-2 from the American Type Culture Collection, FITC-conjugatcd rabbit anti-rat IgG, rhodaminc-conjugated goat anti-rabbit IgG, and S-100 from Bio-Makor (Israel).

Immunoblot analysis. Tissues were extracted in PBS $(100 \mu \mathrm{l} / \mathrm{mg}$ wet weight), containing $1 \%$ Triton $\mathrm{X}-100$, and the protease inhibitors phenylmethylsulfonyl fluoride $(100 \mu \mathrm{g} / \mathrm{ml})$ and aprotinin $(1 \mu \mathrm{g} / \mathrm{ml})$. Of each tissue, $6 \mu \mathrm{g}$ of protein was separated by $12.5 \%$ SDS-PAGE, and transferred electrophoretically to Immobilon PVDF transfer membrane (Millipore, USA), in Towbin, 20\% methanol, 2.5\% isopropanol for $1 \mathrm{hr}$ at $100 \mathrm{~V}$ using a Mini Trans Blot Cell (Bio-Rad). Nonspecific binding was blocked by incubation with $2 \%$ gelatin in Tris-buffered saline (TBS) for $2 \mathrm{hr}$ at $37^{\circ} \mathrm{C}$, followed by two washes with TBS containing $0.1 \%$ Tween 20 (TBST). Membranes were incubated overnight at $4^{\circ} \mathrm{C}$ with supernates of hybridoma cells producing the rat anti-mouse MAC-2 (mAb M3/ 38 ), and then washed four times with TBST. Alkaline phosphataseconjugated anti-rat IgG and NBT/BCIP substrate were used to detect the primary antibody (Promega).

Determining levels of $M A C-2$ in tissues by ELISA. Nerves were homogenized for $2 \mathrm{~min}$ in $50 \mathrm{~mm}$ sodium carbonate buffer $\mathrm{pH} 10.0$ in a volume of $0.3 \mathrm{ml} / \mathrm{nerve}$, and further incubated for $1 \mathrm{hr}$ at $37^{\circ} \mathrm{C}$. Sodium carbonate $\mathrm{pH} 9.6(0.1 \mathrm{ml} /$ nerve of $0.5 \mathrm{M})$ was added to samples that were then vortexed and centrifuged for $10 \mathrm{~min}$ at $15,000 \times \mathrm{g}$. Protein contents of supernates were determined (Bio-Rad protein assay reagent), protein concentration adjusted to $12.5 \mu \mathrm{g} / \mathrm{ml}$ with sodium carbonate buffer pH 9.6 , and $50 \mu \mathrm{l}$ of serial dilutions was used to coat 96 -well plates (Maxisorb Immuno Plates $96 \mathrm{~F}$ Nunc) overnight at $4^{\circ} \mathrm{C}$. Wells 


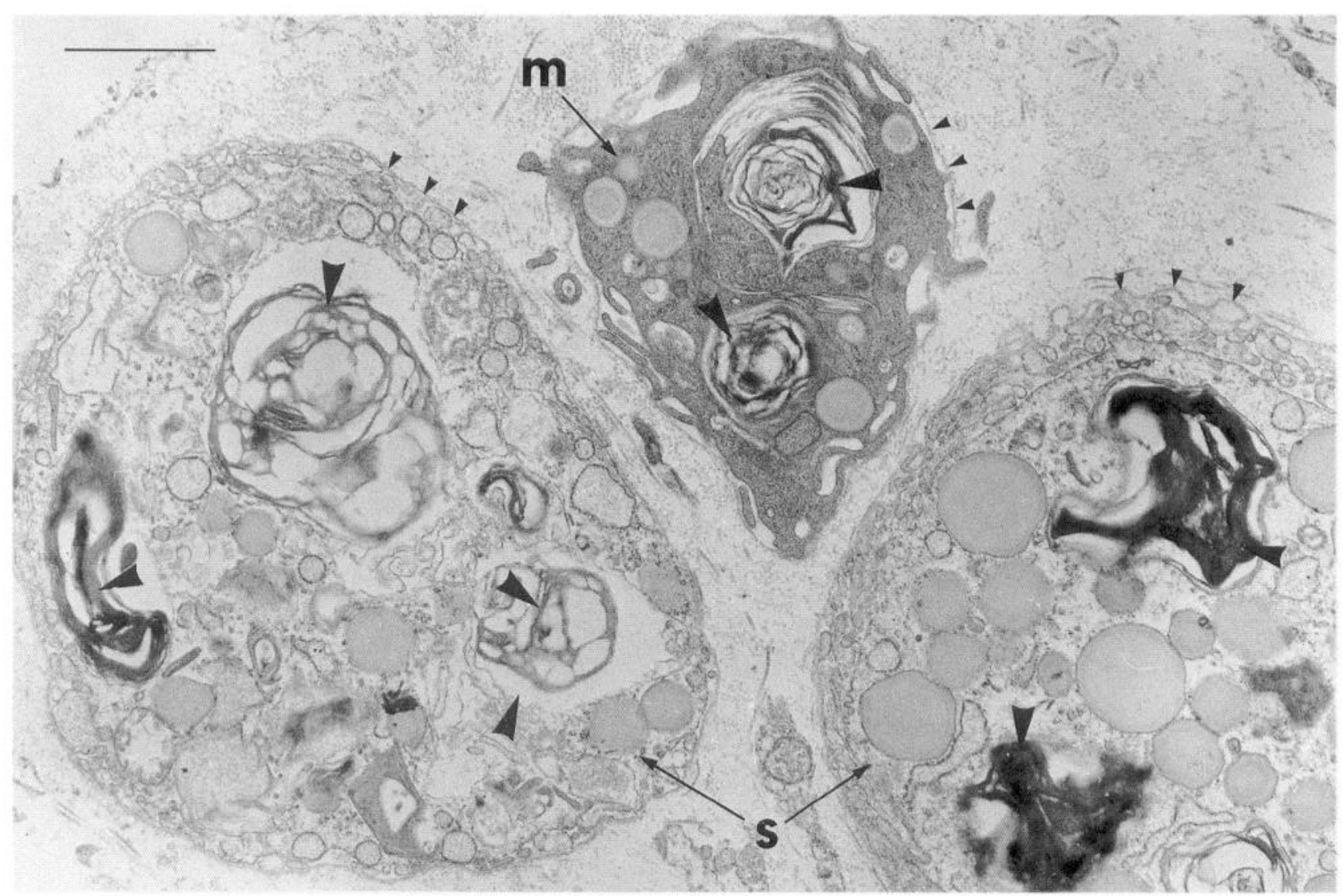

Figure 1. Electron microscopy of $7 \mathrm{~d}$, in vivo degenerating $\mathrm{N}$ mouse nerve cross section. Schwann cells $(s)$ are present within their basal lamina sheath (small arrowheads). Their ribosome-rich cytoplasm contains phagocytized myelin (large arrowheads) and lipid droplets. A macrophage ( $m$ ) with its characteristic filopodia is present within a Schwann cell's basal lamina sheath. Its dark cytoplasm contains phagocytized myelin and lipid droplets. Scale bar, $2 \mu \mathrm{m}$.

were washed $\times 2$ with Tris-buffered saline (TBS), blocked for $2 \mathrm{hr}$ at $37^{\circ} \mathrm{C}$ with $2 \%$ gelatin (Sigma) in TBS, washed $\times 2$ with $0.1 \%$ Tween 20 in TBS (TBST), incubated over night at $4^{\circ} \mathrm{C}$ with $\mathrm{mAb} \mathrm{M} 3 / 38$ (diluted $1: 50$ in $1 \%$ BSA in PBS), washed twice with TBST, incubated for $1 \mathrm{hr}$ in a 1:5000 dilution (in 1\% BSA in 50 mм Tris, $100 \mathrm{~mm} \mathrm{NaCl}$, pH 8.0 ) of alkaline phosphatase-conjugated goat anti-rat IgG (Jackson), washed four times in PBS, and incubated for as long as required at room temperature with substrate solution $(1 \mathrm{mg} / \mathrm{ml} p$-nitrophenyl phosphate sodium in $10 \%$ diethanolamine, $\mathrm{pH} 9.8$; Sigma). The reaction product was read in a Dynatec Elisa reader at $405 \mathrm{~nm}$ wavelength.

Electron microscopy. Tissues were fixed for $2 \mathrm{hr}$ in Karnovsky, $1 \mathrm{hr}$ in $2.5 \%$ glutaraldehyde, $1 \mathrm{hr}$ in $2 \%$ osmium, dehydrated, and embedded in Araldite. Thin sections were examined in the electron microscope.

Morphometric analysis of unphagocytized residual myelin. Nerve cross sections were obtained from intact, in vivo degenerating, in vitro degenerating, and frozen nerves. The sections from in vivo degenerating nerves were taken $5 \mathrm{~mm}$ distal to sites of nerve transection. One-micrometerthick sections were photographed and printed at a total magnification of $700 \times$. A matrix composed of 450 cross points (nine vertical lines spaced $2 \mathrm{~cm}$ apart, over 50 horizontal lines spaced $0.5 \mathrm{~cm}$ apart) was used. The number of unphagocytized myelin profiles that overlapped matrix cross points was counted, thus giving a measure for the density of unphagocytized, residual myelin. Unphagocytized, residual myelin profiles were characterized as round-shaped myelin profiles enclosing a translucent space. In nerve explants, some of these profiles were not associated with Schwann cells and thus were regarded as rejected myelin. Frequently, these figures were collapsed and distorted from a perfect doughnut shape. Fragments of compact and dense myelin were considered phagocytized and/or processed. These criteria are based on our electron microscopic studies (see Results). The validity of this methodology is evident from the reproducibility of the results and the differences between intact and in vivo degenerating $\mathrm{N}$ mouse nerves (see Results). The person performing the counting was unaware of the source tissue.

\section{Results}

Myelin phagocytosis in injured $N$ mouse peripheral nerves

Intact and injured nerves were examined electron microscopically. In intact nerves, Schwann cells outnumbered all other non-neuronal cell types. Fibroblasts were associated primarily with the epineural sheath at the perimeter of nerve trunks. Macrophages were rarely present. In contrast, macrophages were frequently observed 5-7 d after nerve section in nerve segments undergoing Wallerian degeneration (Fig. 1). They were identified as macrophages by their dark cytoplasm, which was relatively poor in free ribosomes and abundant in rough endoplasmic reticulum, irregular nuclear surface, and characteristic filopodia (see also Fig. 2; reviewed in Papadimitriou and Ashman, 1989). Macrophages were present either inside or outside Schwann cells' basement membranes. Macrophages contained fragmented myelin and lipid droplets, indicating their involvement in the phagocytosis and metabolism of myelin. Schwann cells were distinguished from macrophages by their translucent cytoplasm that was rich in free ribosomes and poor in rough endoplasmic reticulum, smooth nuclear surface, and their presence inside basement membranes (Fig. 1). Myelin fragments and lipid droplets were frequently detected within their cytoplasm. Thus, Schwann cells, too, phagocytized and processed myelin.

Intact nerves were explanted into culture and allowed to degenerate in vitro for 5-7 d (not shown). Axons disintegrated, and Schwann cells became separated from their myelin. Schwann cells and rejected myelin were contained within basement mem- 

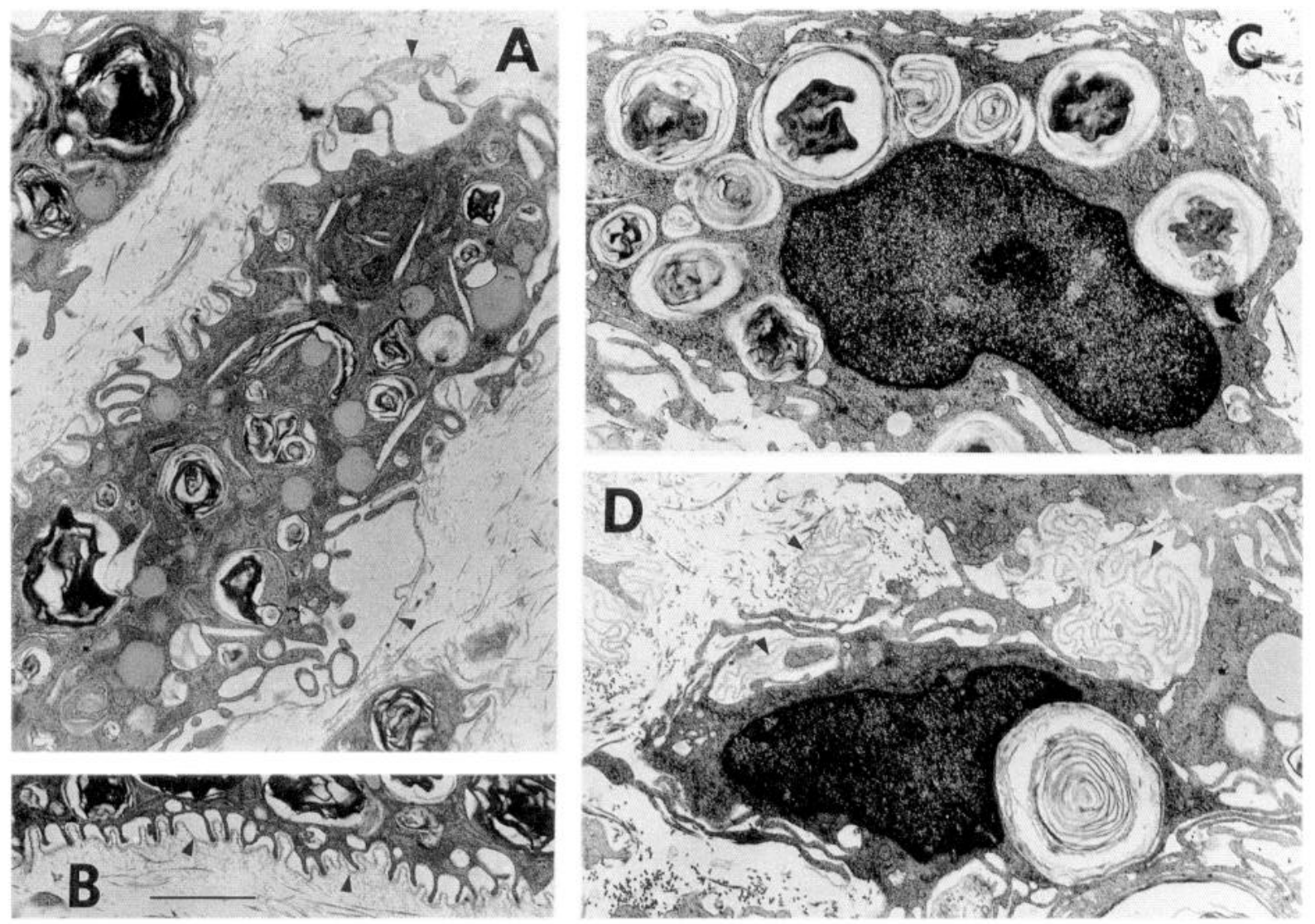

Figure 2. Electron microscopy of cross sections through $7 \mathrm{~d} \mathrm{~N}$ mouse frozen nerve segments. Macrophages that are present either inside $(A$ and $B$ ) or outside $(C$ and $D$ ) Schwann cells' basal lamina sheaths contain phagocytized myelin and lipid droplets. Macrophages adhere to the internal surface of basal laminae through their filopodia $(A$ and $B)$. Scale bar, $2 \mu \mathrm{m}$.

branes. Macrophages were rarely present, and fibroblasts were associated with the epineural sheath at the perimeter of nerve trunks. As in in vivo degenerating nerves, myelin fragments and lipid droplets were detected in the cytoplasm of Schwann cells, further indicating their involvement in myelin phagocytosis.

Nerve segments that had been first freeze thawed to kill nonneuronal cells became populated by macrophages $5-7 \mathrm{~d}$ thereafter (Fig. 2). Occasionally, fibroblasts and polymorphonuclear cells were also detected. The vast majority of macrophages were loaded with myelin fragments and lipid droplets. Some macrophages were present inside, and others outside Schwann cells' basement membranes. Interestingly, macrophages attached to basement membranes by filopodia at the internal but not external surfaces of basal lamina. Many profiles of vacant, collapsed basement membranes were observed.

Neuroma nerve segments (not shown) contained regenerating axons, growth cones, Schwann cells, macrophages, and fibroblasts. Interestingly, yet unexplained, close appositions were observed between axonal growth cones and macrophages. Fibroblasts, identified by their translucent, rough endoplasmic reticulum-rich cytoplasm, appeared in large numbers at tips of neuromata. Some fibroblasts had myelin fragments within their cytoplasm, suggesting their possible involvement in phagocytic activity at this site.

\section{$M A C-1, M A C-2$, the F4/80 antigen, and the Fc receptor in normal and injured $N$ mouse peripheral nerves}

The molecules MAC-1, MAC-2, the F4/80 antigen, and the Fc receptor are characteristically expressed by inflammatory and mature murine macrophages (e.g., Austin and Gordon, 1981; Nibbering et al., 1987; van-Fourth, 1988; Papadimitriou and Ashman, 1989). We studied their expression in intact and lesioned nerves by immunofluorescence light microscopy. The $\mathrm{F} 4 / 80$ antigen is considered to be unique to all mature monocytes/macrophages and hence can be used as a reliable marker for the presence or absence of macrophages. In agreement with our electron microscopic observations, macrophages (F4/80positive cells) are scarce in intact and in in vitro degenerating nerves, but are numerous in neuroma, in vivo degenerating, and frozen nerves (Fig. $3 F-J$ ). Immunoreactivity to MAC-1, MAC2 , and the Fc receptor was rarely detected in intact nerves. In contrast, immunoreactivity was detected in $5-7 \mathrm{~d}$ in vivo degenerating, neuroma, and frozen nerve segments (Fig. $3 A-D$ for MAC-2). Since macrophages can express the three molecules,

Figure 3. Immunocytochemical detection of MAC-2 by mAb M3/38 $(A-E)$ and the $\mathrm{F} 4 / 80$ antigen $(F-J)$ in intact $(A$ and $F)$, neuroma $(B$ and $G)$, in vivo degenerating $(C$ and $H)$, frozen $(D$ and $I)$ and in vitro degenerating $(E$ and $J) \mathrm{N}$ mouse nerves. Immunoreactivity to MAC-2 is not detected in intact peripheral nerves. It is abundant in $7 \mathrm{~d}$ : neuroma $(B)$, in vivo degenerating $(C)$, frozen $(D)$, and in vitro degenerating $(E)$ nerves. 

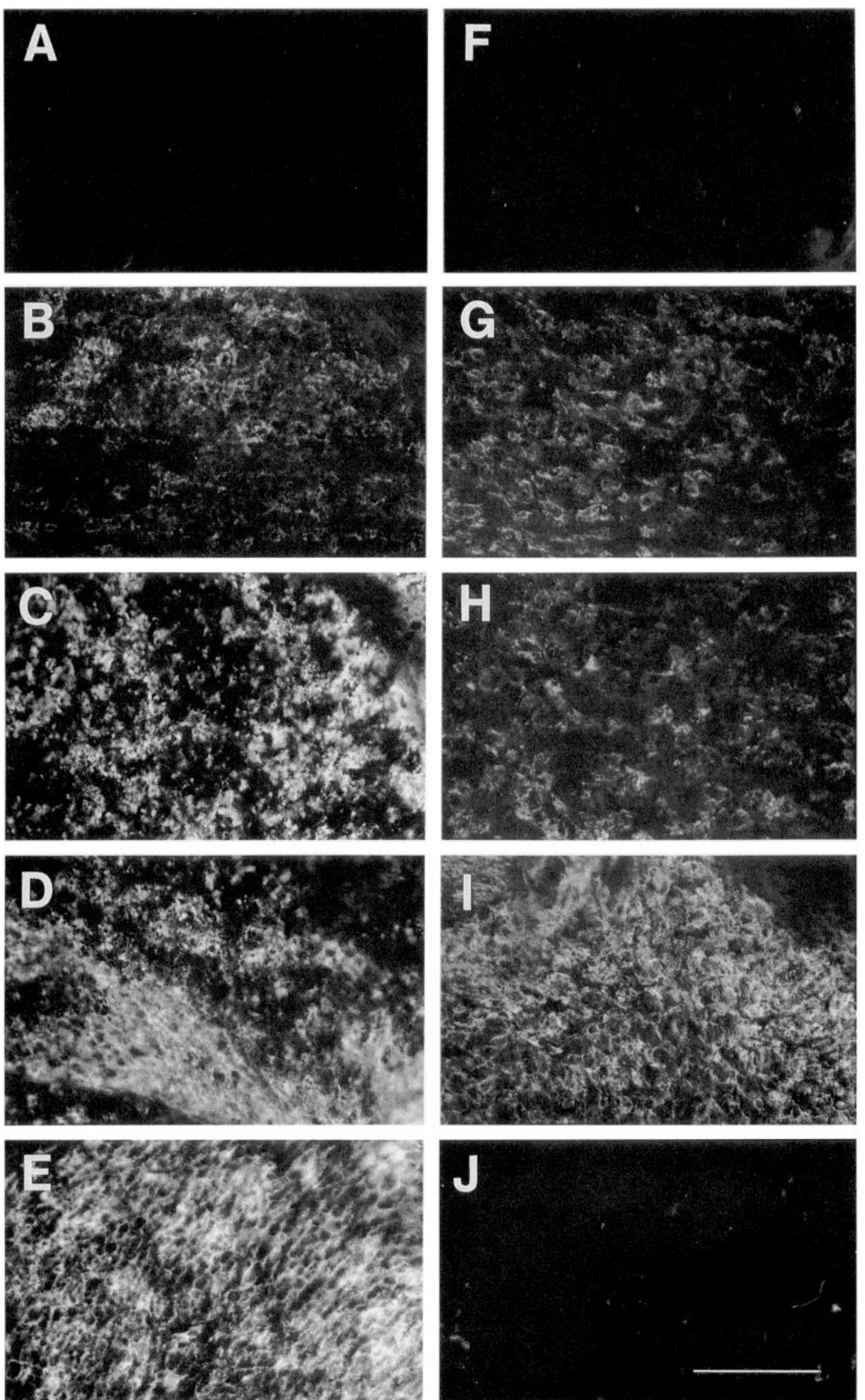

Immunoreactivity to the $\mathrm{F} 4 / 80$ antigen, a marker specific of macrophages, is scarce in intact $(F)$ and in $7 \mathrm{~d}$ in vitro degenerating $(J)$ nerves, and is abundant in $7 \mathrm{~d}$ neuroma $(G)$, in vivo degenerating $(H)$, and frozen $(I)$ nerves. The distribution of immunoreactivity to MAC-2 and the F4/80 antigen was similar all along in vivo degenerating nerves that were sampled from the lesion site and up to $10 \mathrm{~mm}$ distal to it. Scale bar, $400 \mu \mathrm{m}$. 

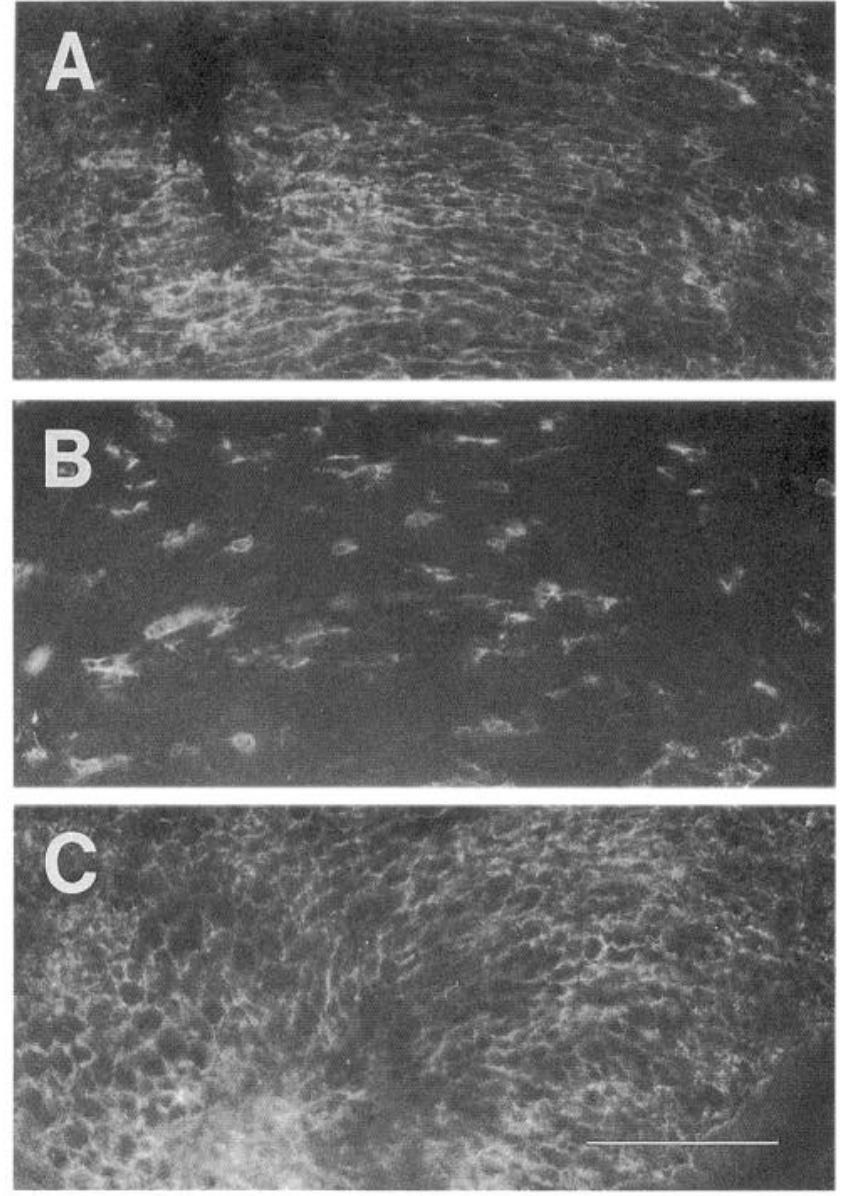

Figure 4. Immunocytochemical detection of MAC-2 by mAb M3/38 $(A$ and $C$ ) and the $\mathrm{F} 4 / 80$ antigen $(B)$ in $2.5 \mathrm{~d}$ in vivo degenerating $\mathrm{N}$ mouse nerves. The stain for MAC-2 is densely and widely distributed. It assumes tube-like $(A)$ and ring-like $(C)$ structures in longitudinal and cross sections, respectively. The stain for the F4/80 molecule is not as dense as the stain for MAC-2. Scale bar, $400 \mu \mathrm{m}$.

the findings correlate well with our electron microscopic and immunocytochemical (F4/80) observations of the rare occurrence of macrophages in intact nerves, and their presence in in vivo degenerating, frozen, and neuroma nerve segments. Surprisingly, a substantial increase in MAC-2 immunoreactivity was detected in 5-7 $\mathrm{d}$ in vitro degenerating nerve explants where macrophages are few (Fig. $3 E, J$ ). The same nerve explants that displayed increased MAC-2 expression did not display similar increases in immunoreactivity to either the F4/80 antigen, MAC1, or the Fc receptor: there was either no change, or very little increase in immunoreactivity to these molecules. Several conclusions can be drawn from these observations. Non-neuronal cells that reside in intact normal peripheral nerves, Schwann cells included, do not express MAC-2. Macrophages that are

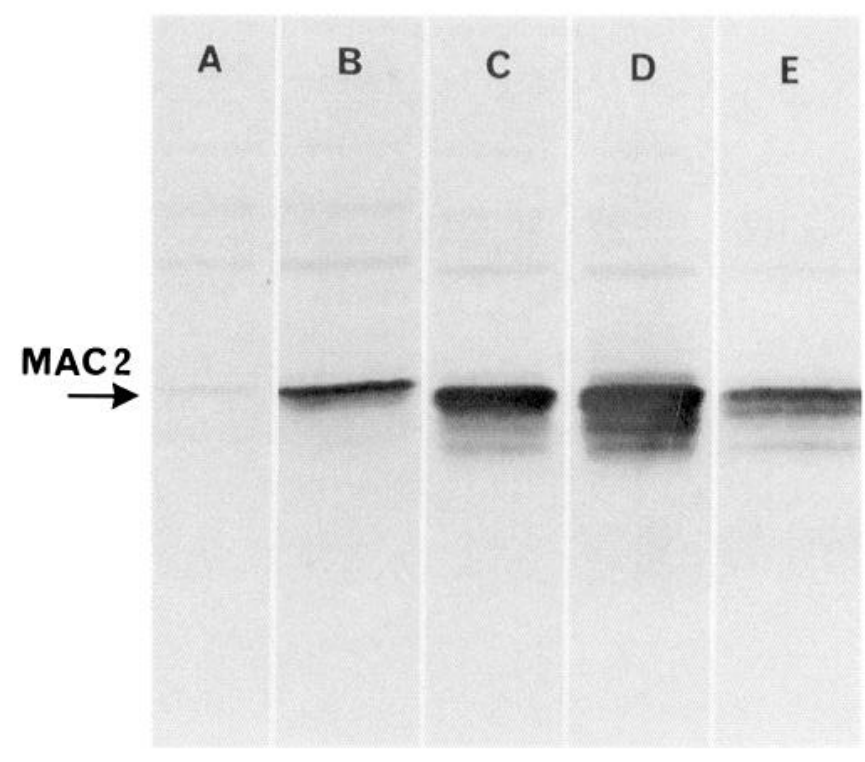

Figure 5. Immunoblot detection of MAC- 2 by mAb M3/38 in extracts of intact $(A)$, and $7 \mathrm{~d}$ : neuroma $(B)$, in vivo degenerating $(C)$, frozen $(D)$, and in vitro degenerating $(E) \mathrm{N}$ mouse nerves. MAC-2 (arrow) and its lower-molecular-weight degradation products are detected in all extracts but that of intact nerve.

scarce in in vitro degenerating nerves cannot account for the wide distribution of MAC-2 presentation in this tissue. By comparison to the electron microscopic observations, the wide distribution of MAC-2 in in vitro degenerating nerves correlates with the anatomical distribution of Schwann cells and no other cell type. The same is the case in $2-3 \mathrm{~d}$ in vivo degenerating nerves (Fig. 4). During this period of time, macrophage recruitment has just begun, not yet reaching their highest density as in later days. Immunoreactivity to MAC-2, however, is densely and widely distributed in ring-like shapes, correlating with the anatomical distribution of Schwann cells, strongly suggesting that they express MAC-2 during in vivo degeneration as they do during in vitro degeneration.

We further verified the lesion-induced increase in MAC-2 expression by immunoblot analysis (Fig. 5). The M3/38 mAb identified a major $31 / 32 \mathrm{kDa}$ protein band and some lowermolecular-weight protein bands. The $31 / 32 \mathrm{kDa}$ protein is MAC2 , and the lower-molecular-weight proteins are its degradation products (Ho and Springer, 1982). MAC-2 was barely detected in extracts of intact nerves. It was clearly detected in substantial, though varying, amounts in neuroma, in vivo degenerating, frozen, and in vitro degenerating explants.

\section{$M A C-2$ expression by isolated and identified $N$ mouse macrophages and Schwann cells}

To determine which cell types express MAC-2 following nerve injury, we examined the presence of the molecule in cells that

Figure 6. Immunocytochemical detection of MAC-2 by mAb M3/38 in non-neuronal cells that migrated out from in vitro degenerating $\mathrm{N}$ mouse nerves during $7 \mathrm{~d}$ of explantation. The micrographs display two fields: $A-C$ and $D-F$. $A$ and $D$, combined immunofluorescence and phase; $B$ and $E$, phase; and $C$ and $F$, immunofluorescence light microscopy. In the first field $(A-C)$, macrophages are the only cells stained by mAb M3/38 $(A$ and $C$ ). They contain granules $(B)$ and vacuoles $(C)$ in their cytoplasm. None of the many fibroblasts that appear in the background are stained by $\mathrm{mAb}$ M3/38. In the second field $(D-F)$, many Schwann cells, fibroblasts, and one macrophage are present. Schwann cells $(s)$ appear in phase as dark, bipolar, spindle-shaped and cytoplasm-poor cells $(E)$. Most of them are stained by mAb M3/38 $(D$ and $F)$. In this field, the single macrophage $(\mathrm{m})$, and one out of the many fibroblasts are also stained by the mAb. Scale bar, $400 \mu \mathrm{m}$. 

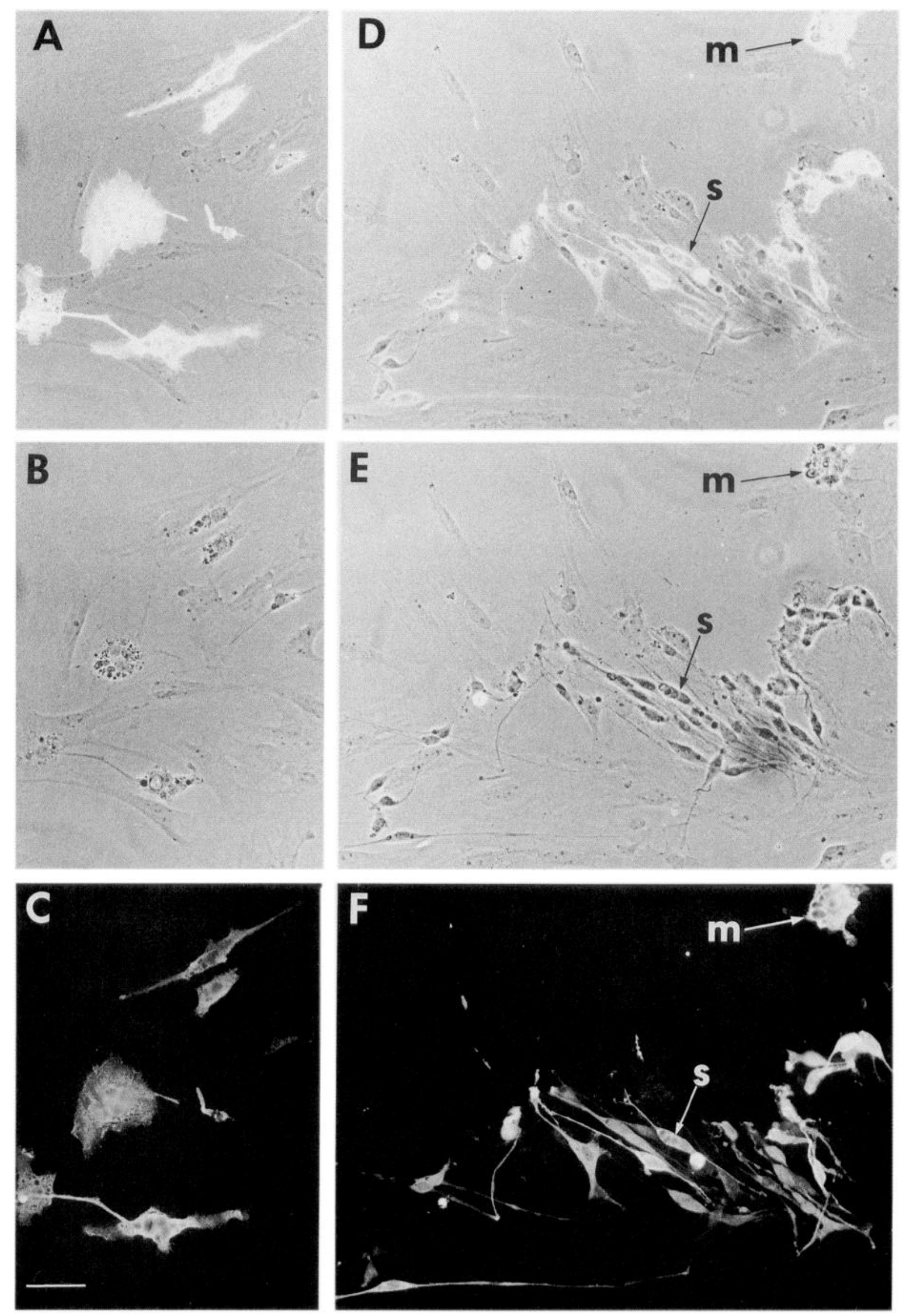
Figure 7. Schwann cells coexpress the S-100 molecule and MAC-2. Cells were dissociated from $\mathrm{N}$ mouse nerves and double stained immunohistochemically by antiserum raised against the $\mathrm{S}-100$ molecule $(A$ and $C)$ and $\mathrm{mAb} \mathrm{M} 3 / 38$ $(B$ and $D$ ). Scale bar, $400 \mu \mathrm{m}$.
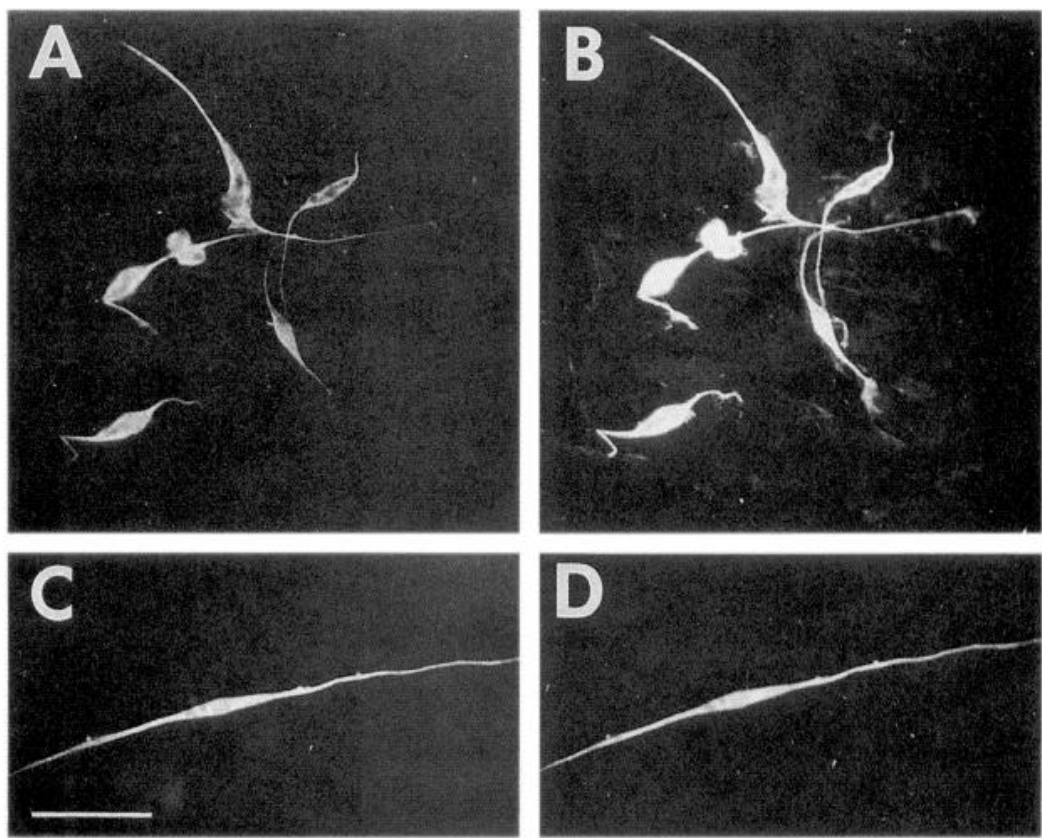

migrated out of, or were dissociated from, injured peripheral nerves. Three cell types dominated cultures of cells that originated from in vivo degenerating nerves: macrophages, Schwann, and fibroblasts. When in vitro degenerating nerves were the source tissue, macrophages constituted only a very small proportion of the cell population. Cells were examined after immunocytochemical staining by phase and fluorescence light microscopy (Fig. 6). The three cell types differed from each other by their distinct morphology and pattern of staining. Macrophages appeared as cytoplasm-rich cells, containing numerous vacuoles and granules. Soon after plating they displayed a round shape. With time they assumed diverse shapes, extending largediameter processes and/or very fine filopodia. These cells were stained by the mAb F4/80 antigen, as expected (not shown for $\mathrm{N}$ mouse macrophages, but see Fig. $15 \mathrm{~B}$ for $\mathrm{W}$ mouse macro-

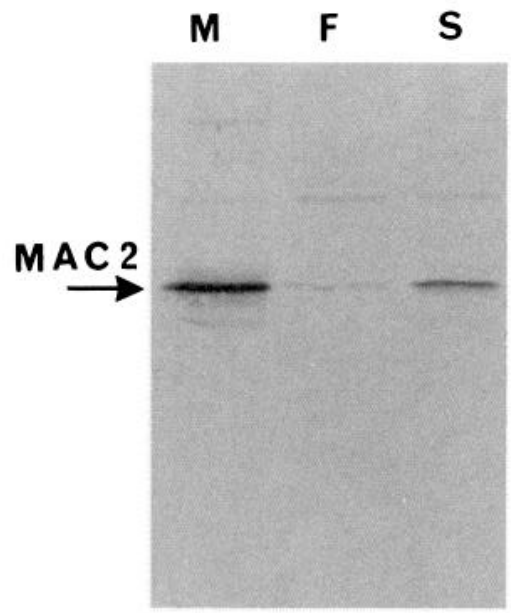

Figure 8. MAC-2 is present in isolated macrophages and Schwann cells but not fibroblasts that were obtained from $5 \mathrm{~d}$ in vivo degenerating nerves. Immunoblot detection of MAC- 2 by $\mathrm{mAb} \mathrm{M} 3 / 38$ in extracts of single cell cultures of macrophages $(M)$, fibroblasts $(F)$, and Schwann cells $(S)$ dissociated from $\mathrm{N}$ mouse nerves. phages). Schwann cells appeared as spindle-shaped, bipolar/tripolar, cytoplasm-poor cells. On laminin-coated dishes, Schwann cells extended particularly very long and thin processes. In many, vacuoles were present at their center portion where cytoplasm was relatively more abundant. These cells were further identified as Schwann cells immunohistochemically by antisera raised against the S-100 molecule (Fig. 7), which in the peripheral
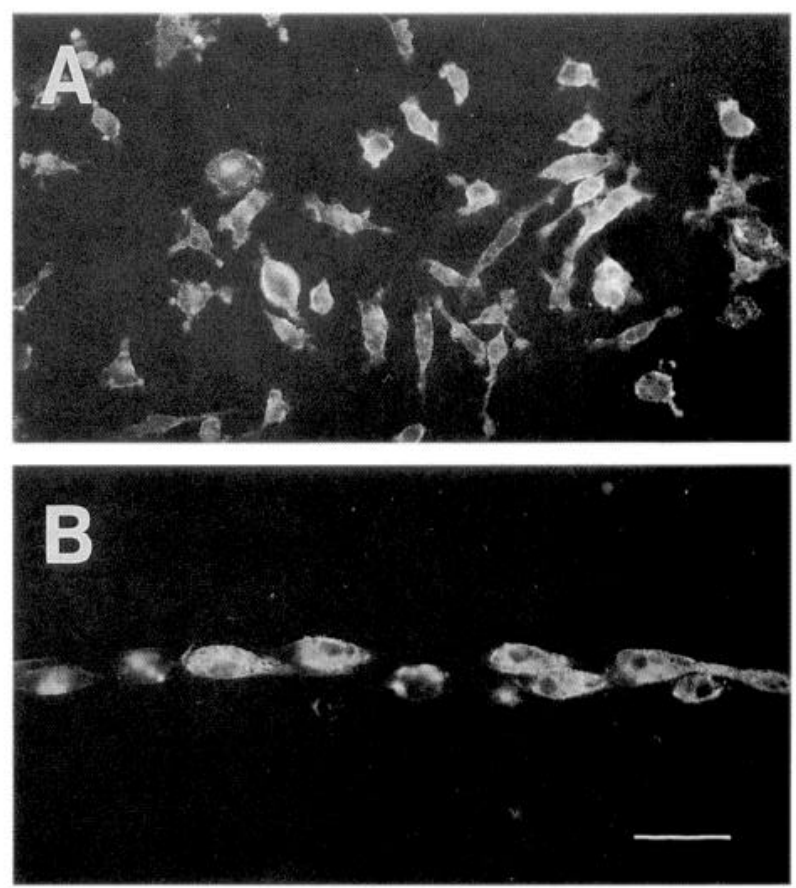

Figure 9. Macrophages $(A)$ and Schwann cells $(B)$ that reside in in vivo degenerating $\mathrm{N}$ mouse nerves express MAC-2 on their surface. The cells were allowed to migrate out of $5 \mathrm{~d}$ in vivo degenerating nerve segments, and then stained with $\mathrm{mAb} \mathrm{M} 3 / 38$ in the absence of Triton X-100. Scale bar, $400 \mu \mathrm{m}$. 

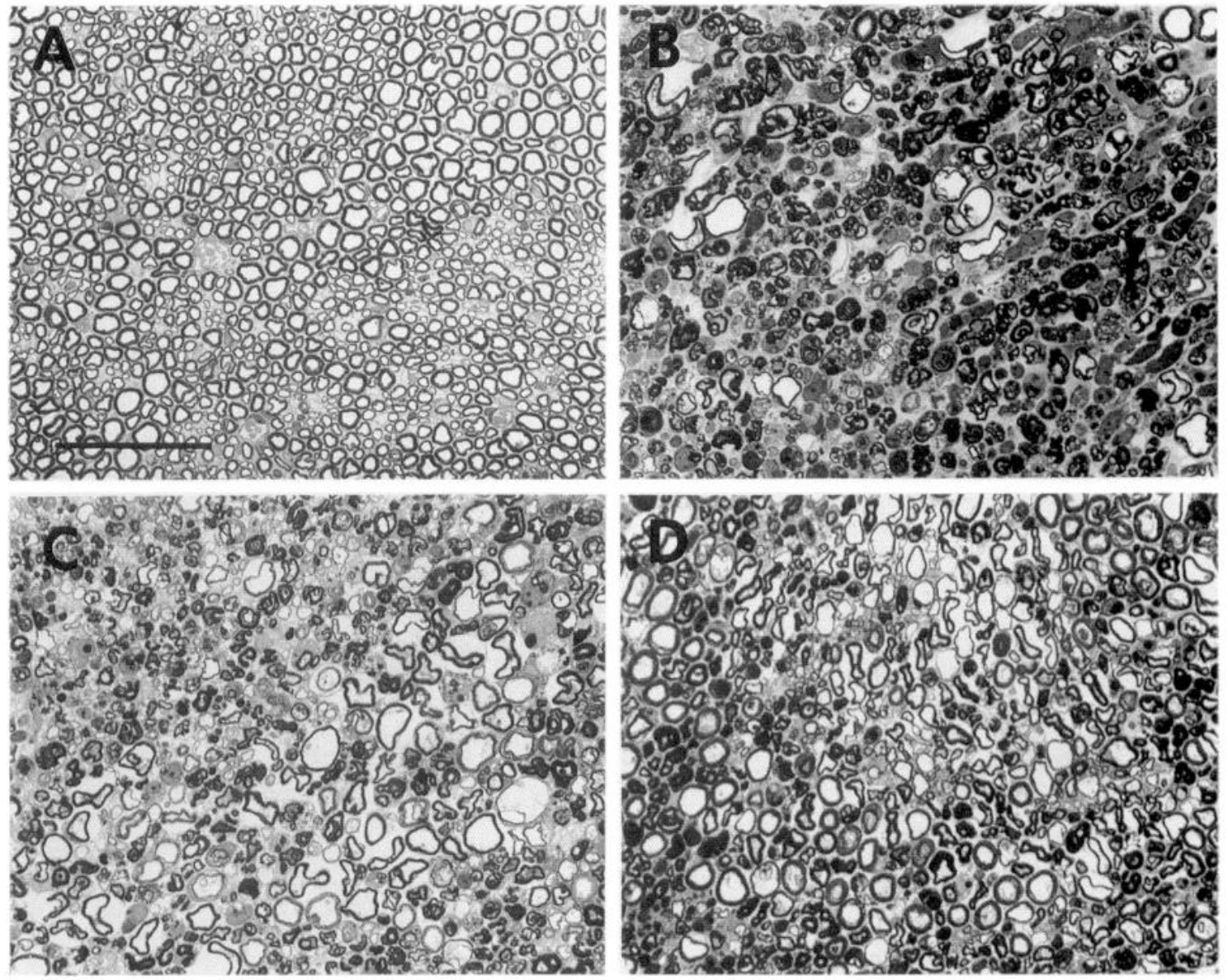

Figure 10. Cross sections through $\mathrm{N}$ mouse nerves: intact $(A)$, and in vitro degenerating nerves that were explanted into culture for $6 \mathrm{~d}$ in the presence of $25 \mathrm{~mm}$ mannose $(B)$, galactose $(C)$, or lactose $(D)$. Intact myelin figures assume the classical doughnut-shaped morphology in intact nerve $(A)$. There is a marked reduction in the density of intact myelin in the various nerve explants, but more so in the mannose-treated $(B)$ than in the galactose $(C)$ - and lactose $(D)$-treated ones. Scale bar, $900 \mu \mathrm{m}$.

nerves is specific to Schwann cells (Stefansson et al., 1982; see also Morrissey et al., 1991). The possibility that these cells are macrophages of some peculiar morphology was further ruled out by the fact that they did not stain for the F4/80 antigen (not shown). Fibroblasts appeared as flat, cytoplasm-rich cells. Their nuclei were very distinct, and often, two nucleoli were associated with each nucleus.

To visualize both surface-associated and cytoplasmic MAC2 , cells were stained immunohistochemically by $\mathrm{mAb} \mathrm{M} 3 / 38$ in the presence of Triton X-100. Macrophages, Schwann cells, and fibroblasts differed in their frequency and intensity of staining. Differences could best be studied when all three cell types were present in the same culture, and thus stained simultaneously. Figure 6 displays cells that migrated out of nerve explants that were left in culture for 1 week. All macrophages stained moderately to most intense by the mAb. The majority of Schwann cells were also stained by the $\mathrm{mAb}$. Some displayed intense and others moderate staining. In contrast, the vast majority of fibroblasts did not stain by the mAb. Of those stained, most displayed weak staining intensity. A similar pattern of $\mathrm{mAb}$ staining was obtained in cells originating from nerve segments that underwent Wallerian degeneration in vivo. The immunocytochemical detection of MAC-2 in Schwann cells and macrophages in cell cultures was further confirmed by immunoblot analysis of extracts of single cell type cultures (Fig. 8).
Using Triton-X 100, the mAb stain appeared throughout the stained cells (Figs. 6, 7). In contrast, when Triton X-100 was omitted and only cell surface-associated MAC- 2 was visualized, the staining pattern of macrophages and Schwann cells was not uniform but rather patchy (Fig. 9). The extent of surface membrane associated with the stain differed pending on the procedure used to obtain cells. A large proportion of surface membrane was stained when cells were allowed to migrate out of in vivo or in vitro degenerating nerve segments. Minute portions of membrane were stained following enzymatic dissociation. The extent of cell surface staining was also extensive in the tissue itself. This was evident from staining of mechanically teased fibers from $8 \mathrm{~d}$ nerve explants.

\section{Inhibition of myelin phagocytosis by galactose and lactose during in vitro degeneration of $N$ mouse nerve explants}

Lectinophagocytosis is a mechanism of phagocytosis dependent on the ability of a phagocyte to identify its specific target by molecular fitting between a cell surface-associated carbohydrate-binding protein (the lectin) and a complementary sugar on the target (Ofek and Sharon, 1988). In this context, MAC-2 is a galactose-specific lectin that is associated with macrophage and Schwann cell surfaces, and myelin, the phagocytized target, is rich in galactolipids (cerebroside and sulfatide; Oulton and Mezei, 1976). It is unknown whether MAC-2 is involved in 


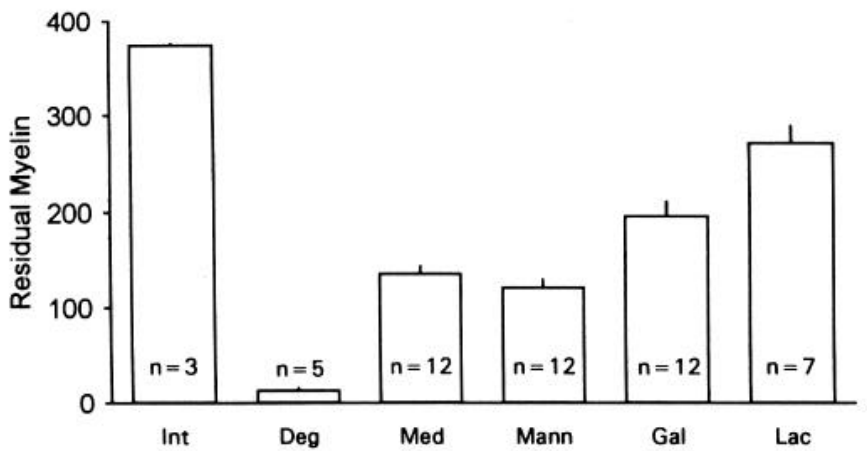

Figure 11. Galactose and lactose significantly and specifically inhibit myelin phagocytosis and consequent destruction in cultures of intact $\mathrm{N}$ mouse nerve explants. Myelin destruction was studied by morphometry to determine the density (in arbitrary units) of intact unphagocytized residual myelin. Intact nerves were explanted into culture for $6 \mathrm{~d}$, and incubated in either medium $(\mathrm{Med})$, or medium supplemented by 25 mM of D-mannose (Mann), D-galactose (Gal), or lactose (Lac). For comparison, densities of intact myelin in intact nerves (Int) and of nerves undergoing in vivo Wallerian degeneration (Deg) for $6 \mathrm{~d}$ are also shown. Values that are smaller than those found in intact nerves express extent of myelin destruction by phagocytosis. Bars represent the average values of residual (intact, unphagocytized) myelin; error bars, 1 SEM; $n=$ number of nerve cross sections examined, each representing a separate nerve taken from different mice. Each one of the same 12 mice contributed to the Med, Man, and Gal experiments, and seven of these to the Lac experiments. Levels of significance of differences were calculated by the Mann-Whitney $U$ test: $P<0.02$ for Gal over Med, $P<$ 0.002 for Gal over Man, $P<0.002$ for Lac over Med and Man, and $P$ $<0.02$ for Lac over Gal.

lectin-mediated phagocytosis. We hypothesized that this could be the case, and therefore tested for the possibility that MAC-2 mediates phagocytosis of myelin. We examined whether or not galactose and lactose will inhibit myelin phagocytosis. Inhibition is expected based on the competition between the free sugars (galactose and lactose) and the myelin galactolipids on binding to MAC-2. Furthermore, it is expected that lactose will be a more potent inhibitor than galactose based on its higher binding affinity to MAC-2 (Frigeri et al., 1990). The use of specific free sugars as competitive inhibitors is the method of choice to test for lectin-mediated phagocytosis in the absence of function-blocking antibodies (Ofek and Sharon, 1988).

Intact nerves from individual mice were distributed between regular medium (DMEM $+10 \%$ FCS) and medium to which $25 \mathrm{~mm}$ of either mannose, galactose, or lactose was added. Nerves were kept in culture for $6 \mathrm{~d}$, and then analyzed by morphometry to assess the density of unphagocytized, residual myelin. Unphagocytized, residual myelin was defined morphologically as round-shaped myelin figures enclosing translucent spaces (Fig. 10). The validity of the morphometric methodology used is evident from the values obtained for intact (374) and in vivo degenerating (13) nerves. The average value of residual myelin in nerve explants incubated in medium (144) did not differ significantly from that in nerve explants exposed to $25 \mathrm{~mm}$ mannose (130). Levels of residual myelin in explants exposed to $25 \mathrm{~mm}$ galactose $(211)$ or lactose $(289)$ were significantly higher than those in explants bathed in regular medium or medium supplemented by mannose (Fig. 11). Galactose and lactose, the competing sugars, but not mannose, the noncompeting sugar, increased residual myelin. Furthermore, lactose was significantly more effective than galactose in this respect, as expected from the higher binding affinity of lactose to MAC-2.
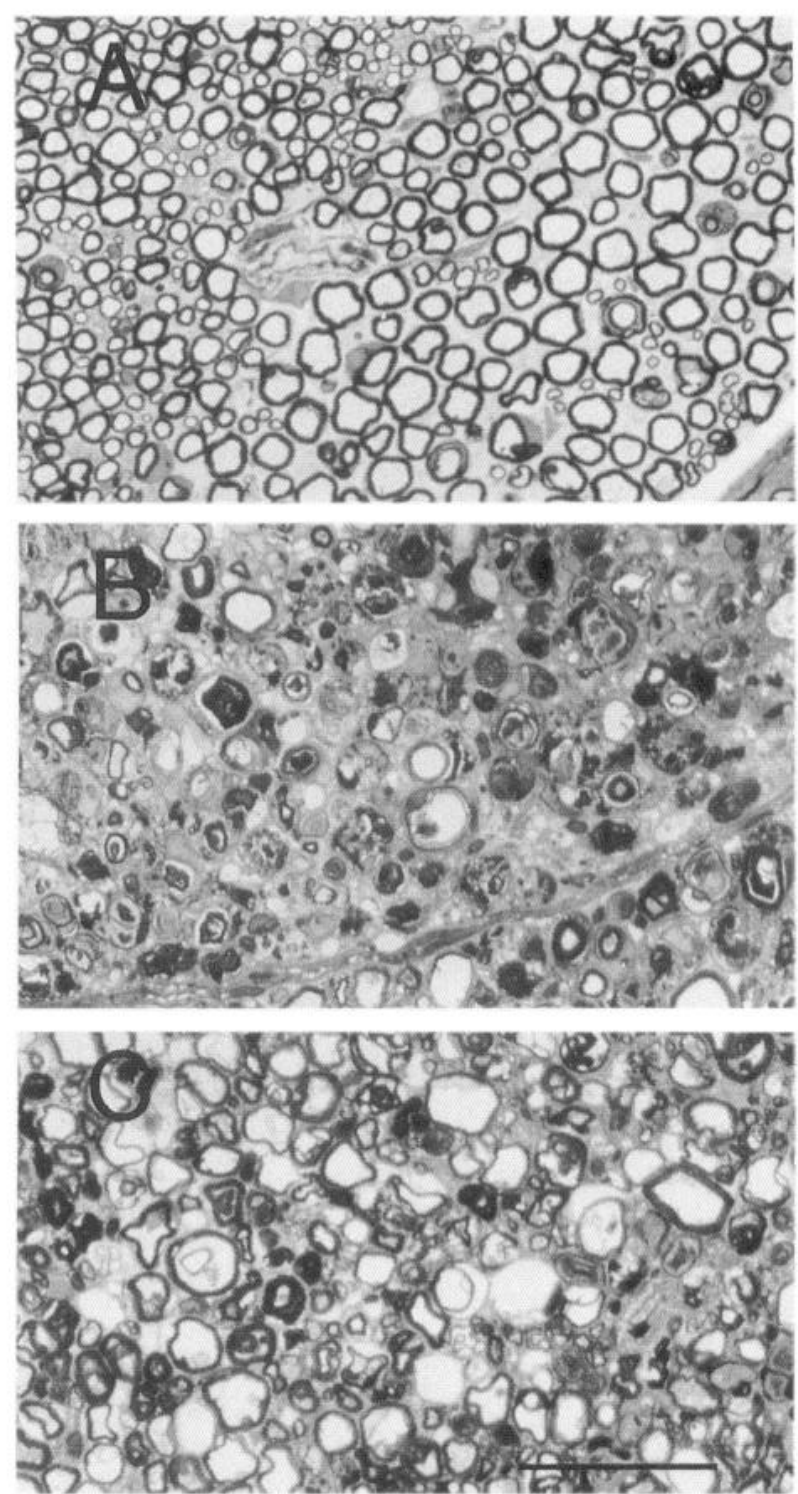

Figure 12. Cross sections through $\mathrm{W}$ mouse peripheral nerves after 6 $\mathrm{d}$ of in vivo $(A$ and $B)$, and in vitro $(C)$ degeneration. The nerve segment located distal to the site of nerve transection was divided into two domains: the distal domain (over $5 \mathrm{~mm}$ from the site of transection) that displays a morphology that is indistinguishable from normal $(A)$, and the injury region (less than $3 \mathrm{~mm}$ from the site of transection) where myelin destruction occurred $(B)$. $C$, Intact nerves that were explanted into culture and allowed to degenerate in vitro exhibit low frequency of myelin destruction. Scale bar, $725 \mu \mathrm{m}$.

Therefore, inhibition of phagocytosis by galactose and lactose is specific and not due to some unspecific effect of sugars.

\section{Myelin phagocytosis in injured $W$ mouse peripheral nerves}

W mice display a slow progression of Wallerian degeneration (Lunn et al., 1989; Perry et al., 1990). At postinjury time intervals that $\mathrm{N}$ mice already exhibit profound destruction of axons and phagocytosis of myelin, W mice display normal morphology. We have repeated those observations and extended them. Sciatic nerves of $\mathrm{W}$ mice were examined by light and electron microscopy 5-7 d after injury (Fig. 12). Nerve segments situated distal to sites of transection were divided into two domains. From the site of transection to about $3 \mathrm{~mm}$, and the 
more distally located portion up to additional $10 \mathrm{~mm}$. The first domain will be referred to as the injury/lesion site/region. In $\mathrm{W}$ mice, the two domains differed in their morphological appearance. Breakdown of axons, recruitment of macrophages, and phagocytosis of myelin were detected at the lesion site (Fig. 12B). The more distal domain appeared normal (Fig. 12A): axons and myelin were intact, and macrophages were as scarce as in intact nerves. In contrast to the findings during in vivo degeneration, some breakdown of axons and myelin phagocytosis were detected throughout $\mathrm{W}$ mouse nerve explants that degenerated in vitro for 5-7 d (Fig. 12C). We have further examined $\mathrm{W}$ mouse nerves that were damaged by cycles of freeze and thaw to extinct of all non-neuronal cells present (e.g., Schwann). The frozen nerves were placed back into the donor animals and examined 5-7 d latcr. Macrophages invaded the frozen nerves and phagocytized myelin.

To estimate the extent of myelin destruction we assessed, by morphometry, the density of unphagocytized residual myelin in intact nerves, in $6 \mathrm{~d}$ in vitro degenerating nerves, and in $6 \mathrm{~d}$ in vivo degenerating nerves ( $>5 \mathrm{~mm}$ distal to injury sites). $\mathrm{N}$ and $\mathrm{W}$ mice were examined (Fig. 13A). In $\mathrm{N}$ mice, myelin destruction was partial during in vitro degeneration (about 64\%) and almost complete during in vivo Wallerian degeneration $(>95 \%)$. In W mice, myelin destruction that occurred during in vitro degeneration was less pronounced than in $\mathrm{N}$ mice (about $23 \%$ ). In marked contrast to $\mathrm{N}$ mice, there was no reduction in the density of unphagocytized myelin during the first $6 \mathrm{~d}$ of in vivo degeneration of $\mathrm{W}$ mouse nerves at regions located farther distal than $5 \mathrm{~mm}$ from sites of transection.

\section{The expression of $M A C-1, M A C-2$, the $F c$ receptor, and the F4/80 antigen in injured $W$ mouse peripheral nerves}

The slow progression of Wallerian degeneration in $\mathrm{W}$ mice has been attributed to the slow-pace recruitment of macrophages distal to the lesion site. The failure to recruit macrophages provides only a partial explanation for the lack of axonal breakdown and myelin phagocytosis. This conclusion is based on the observation that some degree of phagocytosis occurred in vitro but not in vivo, although the same arrays of non-neuronal cells were involved in the two instances. We have suggested that MAC-2 can be involved in the mediation of myelin phagocytosis by Schwann cells and macrophages (see above). Two questions thus arise: (1) whether the failure to show any degree of myelin destruction in vivo resulted from a deficient production of MAC-2 in vivo; (2) whether the in vitro destruction of myelin is associated with MAC-2 production. We studied, therefore, in W mice, as in $\mathrm{N}$ mice (see above), the expression of the molecules MAC-1, MAC-2, the FC receptor, and the F4/80 antigen using immunohistochemistry (see Fig. 14 for MAC-2 and the F4/80 antigen). Very little and often no immunoreactivity to the four molecules was observed in intact nerves. In vivo degenerating nerves were examined at three locations along their length: at the site of injury and 5 and $10 \mathrm{~mm}$ distal to it. Increased immunoreactivity to the four molcculcs was detected at the site of injury but neither at 5 nor $10 \mathrm{~mm}$ distal to it. This finding was in marked contrast to findings in $\mathrm{N}$ nerves where increases in immunoreactivity to the four molecules was detected at the three locations as of the third day after nerve transection. MAC1, MAC-2, the Fc receptor, and the F4/80 antigen were expressed throughout frozen $\mathrm{W}$ nerves. W nerves that were explanted into culture and allowed to undergo in vitro degeneration for 5-7 d expressed higher-than-normal levels of MAC-2, but
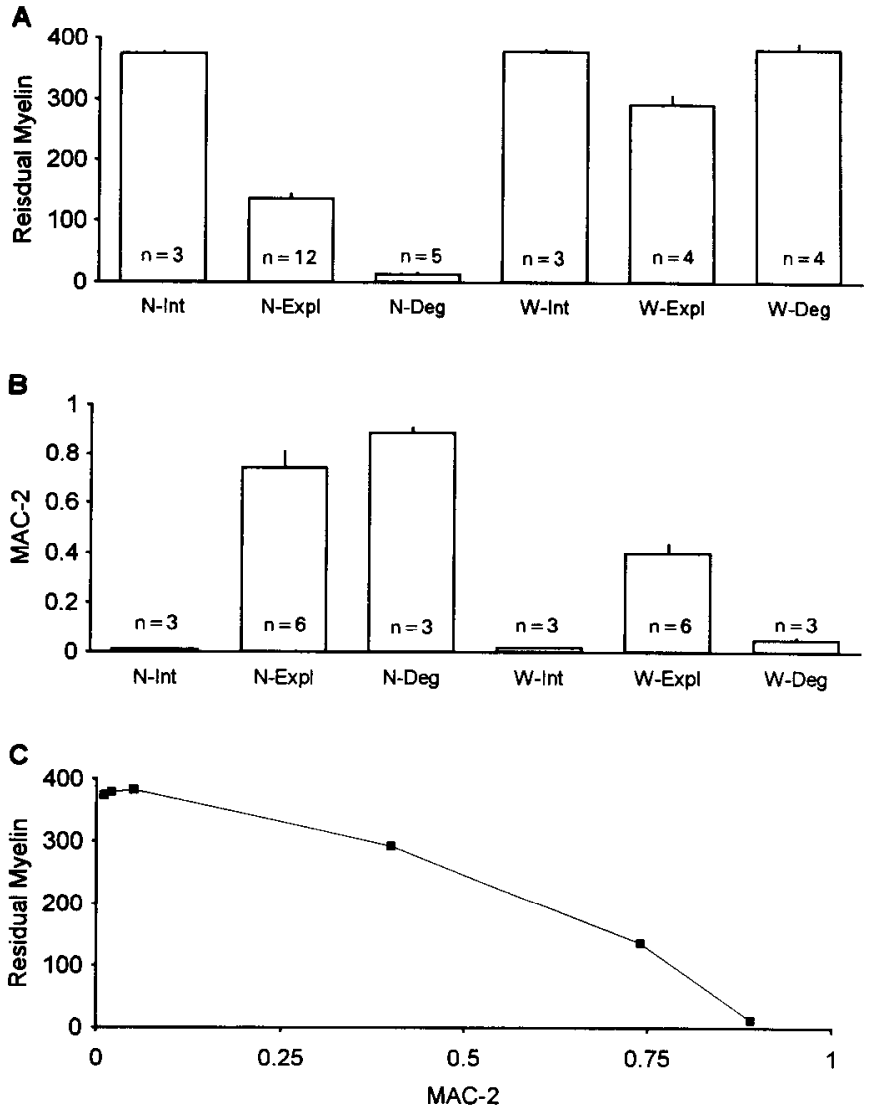

Figure 13. Myelin destruction occurs in nerves that express MAC-2. The extent of myelin phagocytosis and MAC-2 expression were studied in peripheral nerves of mice undergoing rapid $(N)$ and slow $(W)$ Wallerian degeneration in vivo. $A$, Myelin destruction was studied by morphometry to determine the density (in arbitrary units) of intact unphagocytized residual myelin. Tissues were examined $6 \mathrm{~d}$ after surgery. Values shown are for intact nerves ( $I n t)$, nerve explants undergoing in vitro degeneration $(E x p l)$, and nerve segments located farther distal than $5 \mathrm{~mm}$ from sites of nerve transection and thus,allowed to undergo in vivo Wallerian degeneration $(D e g)$. Values that are smaller than those found in intact nerves express extent of myelin destruction by phagocytosis. Bars represent average values; error bars, 1 SEM; $n=$ number of sections examined each taken from a different animal. $B$, Similar tissues were assayed for MAC-2 content by ELISA. Levels of MAC-2 are expressed in optical density units. All samples were tested simultaneously and thus subject to quantitative comparison. Bars represent average values; error bars, I SEM; $n=$ number of independent experiments. $C$, Higher levels of MAC-2 expression are correlated with a larger extent of myelin destruction. Values of residual myelin were taken from $B$ and plotted against values of MAC-2 taken from $A$.

normal levels of the F4/80 antigen, the Fc receptor, and MAC 1. Thus, in W mice, macrophages (the F4/80-positive cells) were recruited in vivo to the site of nerve injury and into frozen nerves (Fig. 14G,I). Macrophages were largely excluded in vitro from nerve explants, and in vivo from intact nerves and injured nerve scgments situated from $3 \mathrm{~mm}$ and farther distal to injury sites (Fig. $14 F, H, J$ ). The distribution of MAC-2-bearing cells paralleled that of macrophages except for in the in vitro degenerating nerve explants where the expression of MAC-2 increased although macrophages remained scarce (Fig. 14E,J). Thus, MAC-2 was present where myelin destruction occurred and was absent where myelin destruction did not take place.

In $\mathrm{W}$ as in $\mathrm{N}$ mouse nerve explants, the increase in the expression of MAC-2 was not accompanied by similar increases 

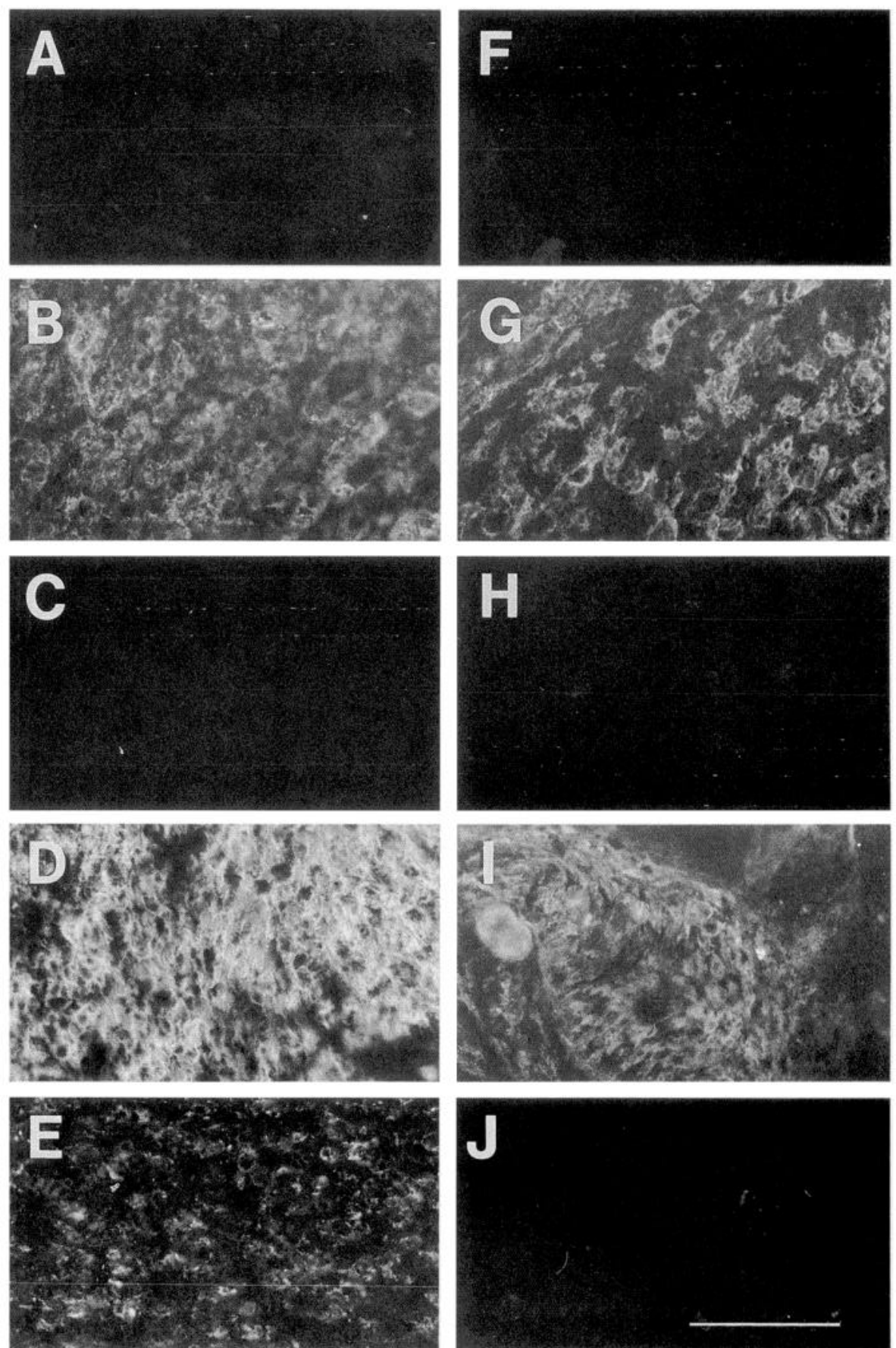

in the expression of the $\mathrm{F} 4 / 80$ antigen, the $\mathrm{Fc}$ receptor, and MAC-1. This suggests that a cell type other than macrophages displayed MAC-2. We have already demonstrated that $\mathrm{N}$ mouse Schwann cells express MAC-2 after nerve injury. To determine whether W mouse Schwann cells do the same, we stained cell cultures immunohistochemically for MAC-2 either in the presence of Triton X-100 to visualize cytoplasmatic and cell surface MAC-2, or in the absence of Triton X-100 to visualize only cell surface MAC-2. Only a proportion W mouse Schwann cells stained for MAC-2 (Fig. 15A). In the presence of Triton X-100, the entire cell stained. In the absence of Triton X-100, the stain was very faint and patchy. Thus, Schwann cells displayed MAC-2 primarily in their cytoplasm and relatively very little on their surface. The few macrophages that were present (identified as F4/80-positive cells; Fig. 15B) stained well for MAC-2 in the presence as in the absence of Triton X-100. Fibroblasts stained neither for F4/80 nor for MAC-2.

To compare $\mathrm{W}$ and $\mathrm{N}$ mice further, we used ELISA to quantify levels of MAC-2 in W and $\mathrm{N}$ mouse nerves (Fig. 13B). We examined intact nerves, $6 \mathrm{~d}$ in vivo degenerating nerves $(>5$ $\mathrm{mm}$ distal to injury sites), and $6 \mathrm{~d}$ in vitro degenerating nerve explants. In intact nerves, MAC-2 was barely detected in the two strains of mice. $\mathrm{W}$ and $\mathrm{N}$ mice differed dramatically in their in vivo response to nerve transection, but much less so in their in vitro response. We further looked at the relationship between the extent of myelin destruction and levels of MAC- 2 over the 

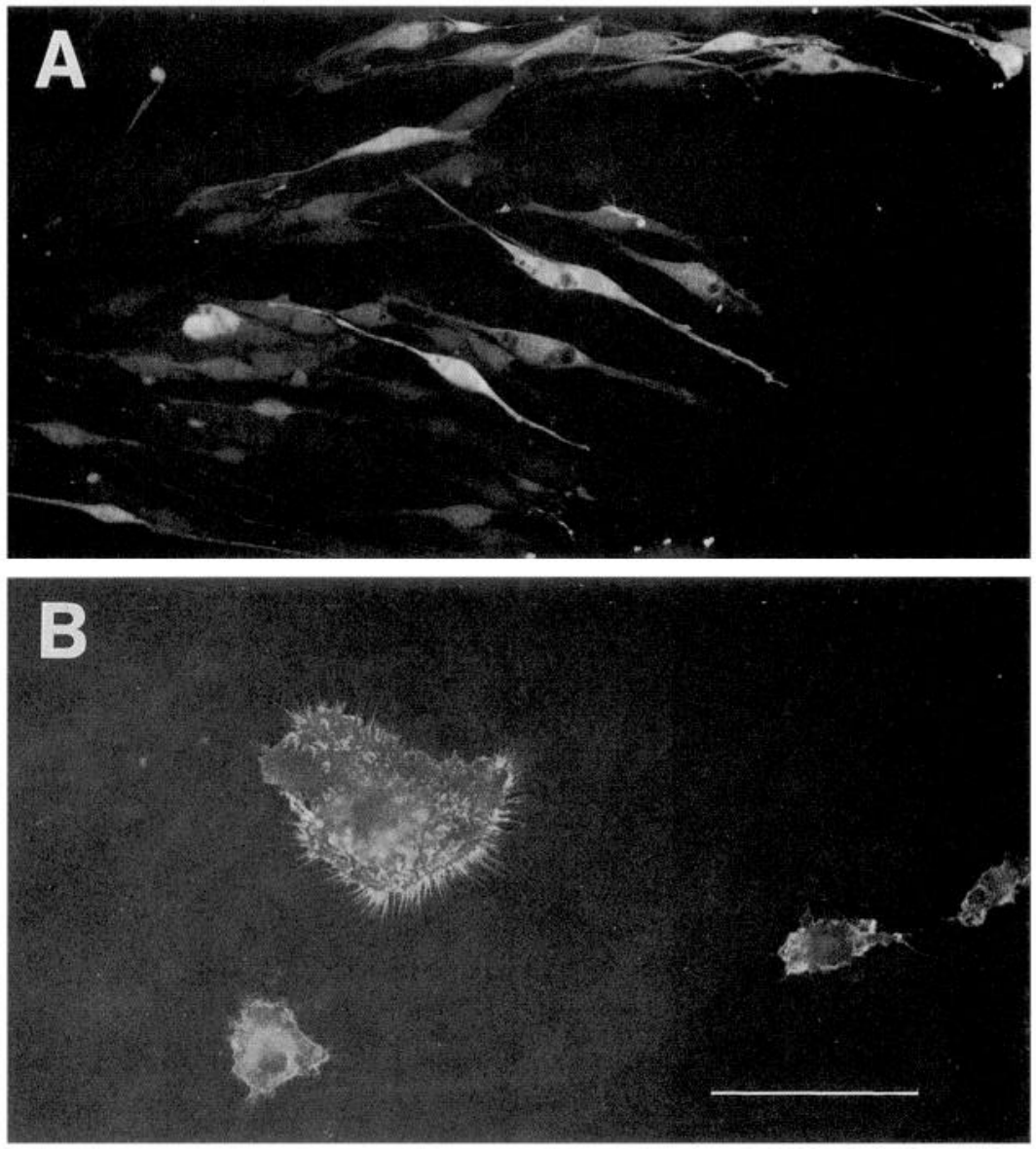

Figure 15. Schwann cells $(A)$ and macrophages $(B)$ were dissociated from W mouse peripheral nerves. In phase light microscopy the morphology of cells originating from $\mathrm{W}$ mice and $\mathrm{N}$ mice is indistinguishable. $A$, Cultured Schwann display bipolar spindle shape morphology and express MAC-2 as revealed by immunocytochemistry. $B$, Macrophages express the F4/80 antigen. Scale bar, $400 \mu \mathrm{m}$. entire range represented by $\mathrm{N}$ and $\mathrm{W}$ nerves (Fig. 13C). It is evident that a strong positive correlation is displayed between the two: higher levels of MAC-2 are associated with an increasing extent of myelin destruction.

\section{Discussion}

In this report we present evidence that injury of normal $\mathrm{N}$ mouse peripheral nerves induces Schwann cells to express the galactosespecific lectin MAC-2 and to phagocytize myelin. These are phenotypes characteristic of blood-borne macrophages that reside in degenerating nerves. We further provide evidence suggesting a functional role for MAC-2 in lectin-mediated myelin phagocytosis. These findings and conclusions are consistent with several situations. The intactness of myelin in normal nerves is associated with the lack of MAC-2 expression by Schwann cells and by the few macrophages present in the tissue. In contrast, during the normal course of Wallerian degeneration Schwann cells and recruited macrophages express MAC-2 that enables the two cell types to display lectinophagocytosis of myelin. Of particular interest is the understanding of the ability of Schwann cells to phagocytize a specific portion of their own membrane, the myelin. This becomes possible secondary to the appearance of MAC-2. In mutant $\mathrm{W}$ mice, the in vivo intactness of myelin in nerve segments situated distal to sites of nerve transection is associated with the failures to recruit macrophages and to induce MAC-2 production by Schwann cells. In both normal and mutant mouse nerves the in vitro destruction of myelin is correlated with the production of MAC- 2 in the tissues.
Myelin phagocytosis by Schwann cells was clearly observed in the electron microscope in nerve segments undergoing in vivo and in vitro axonal degeneration. Our conclusion is based on the electron microscopical identification of and distinction between Schwann and macrophages. Our findings thus conform with those documenting myelin phagocytosis by rat Schwann cells (Bigbee et al., 1987; Stoll et al., 1989). Our findings do not agree with other observations that are also inconsistent between themselves. Myelin phagocytosis was not detected in mouse peripheral nerves undergoing degeneration in diffusion chambers (Beuche and Friede, 1984) but was detected in mouse peripheral nerves undergoing degeneration in culture (Hann Bonnekooh et al., 1989). In the latter study, based on the detection of MAC-1 and the Fc receptor by light microscopy immunocytochemistry in few cells, all electron microscopically detected phagocytes were presumed to be proliferating macrophages and not Schwann cells. Our present electron microscopical and immunocytochemical observations do not support the notion that a substantial increase in macrophage population is taking place in explants of intact nerves secondary to proliferation (see the discussion below). In agreement with our findings are two types of observations. First, in quantitative electron microscopical studies of intact peripheral nerves there is no positive identification of cells as macrophages (Thomas, 1963; Schubert and Friede, 1981). The macrophage population in intact nerves must therefore be very small. Second, only a small proportion of tissue macrophages are capable of cell division, and then of one cycle only (see reviews by van-Furth, 1988; Papadimitriou and Ashman, 1989). 
Several lines of evidence indicate that nerve injury induces Schwann cells to express MAC-2, which normally they do not. Immunocytochemistry and immunoblot analysis of intact peripheral nerves resulted in very little, if any, MAC-2 immunoreactivity. Thus, Schwann cells in intact and normal peripheral nerves do not express MAC-2. During in vitro degeneration of nerve explants, MAC-2-bearing cells become numerous. This increase in MAC-2 presentation, in nerve explants, was not accompanied by similar, concomitant increases in MAC-1, Fc receptor, and $\mathrm{F} 4 / 80$ antigen presentations. Thus, macrophages cannot account for the increase in MAC-2 expression in nerve explants. If macrophages were responsible for the increase in the display of $\mathrm{MAC}-2$, one would expect substantial increases in the expression of the F4/80 antigen if not of all, as was the case in the macrophage-rich tissues (the in vivo degenerating and frozen nerves). The dense and wide anatomical distribution of ring/tube-like shaped structures revealed by the immunocytochemical stain for MAC-2 in in vitro and early in vivo degenerating nerves correlates well with the anatomical distribution of Schwann cells and no other cell type. Finally, MAC-2 was detected by immunocytochemistry and immunoblot analysis in cells isolated from in vivo and in vitro degenerating nerves that were identified as Schwann by their characteristic morphology, S-100-positive and F4/80-negative immunocytochemistry. The difference in the pattern of MAC-2 staining between cells that were or were not treated with Triton X-100 further indicates that MAC-2 is associated with the cytoplasm and the external surface of Schwann cells.

MAC-2 was first identified as a cell surface molecule expressed by inflammatory and mature murine macrophages (Ho and Springer, 1982) and thereafter also by human macrophages (Cherayil et al., 1990). Some, but not all, macrophage-activating factors upregulate MAC-2 expression (Ho and Springer, 1982). Therefore, our detection of the molecule in macrophages that reside in injured nerves was neither surprising nor self-evident. Interestingly, an identical/homologous molecule is also produced by transformed malignant cells: the fibroblast 3T3 cell line (Moutsatsos et al., 1987; Jia and Wang, 1988), rat basophilic leukemia (Liu et al., 1985), and metastasis associated malignancies (Raz et al., 1989, 1991). In view of these observations, the detection of MAC-2 in Schwann cells that, on the one hand, differ in their lineage from macrophages and, on the other hand, are not malignant cells, is unique and novel.

MAC-2 has already been identified as a galactose-specific lectin, a nonintegrin laminin-binding protein, an IgE-binding molecule, and a component of heterogeneous nuclear binding protein (Liu et al., 1985; Moutsatsos et al., 1987; Jia and Wang, 1988; Cherayil et al., 1990; Woo et al., 1990). We propose an additional and novel role for MAC-2. As a cell surface-associated lectin, MAC-2 can mediate myelin phagocytosis through the nonimmune, opsonin-independent mechanism of phagocytosis: lectinophagocytosis (Ofek and Sharon, 1988). In lectinophagocytosis, the ability of a phagocyte to identify its specific target is dependent on a molecular fitting between a cell surfaceassociated carbohydrate binding protein (the lectin) and a complementary sugar on the target. In this context, MAC-2 is a galactose-specific lectin that is associated with macrophage and Schwann cell surfaces, and myelin, the phagocytized target, is rich in galactolipids (Oulton and Mezei, 1976). Present is, therefore, the molecular fitting required by lectinophagocytosis. To test for MAC-2-mediated myelin phagocytosis we have used a methodology most commonly used to test for lectin-mediated phagocytosis, competitive inhibition of phagocytosis by specific sugars (Ofek and Sharon, 1988). Our observations that galactose and lactose but not mannose inhibited myelin phagocytosis strongly suggests, therefore, that MAC- 2 can provide a molecular basis for myelin lectinophagocytosis by Schwann cells. Macrophages, by expressing MAC-1, MAC-2, and the Fc receptor, are capable of phagocytosis using immune as well as nonimmune-related mechanisms. The multiplicity of mechanisms by which macrophages can exercise phagocytosis may be one explanation for the higher phagocytic activity they express.

The observations made in $\mathrm{W}$ mice further support our hypothesis that MAC-2 is mediating myelin phagocytosis. There was in $\mathrm{W}$ mice a mutual absence in vivo and mutual presence in vitro of MAC-2 expression and myelin phagocytosis. Furthermore, there was a quantitative correlation between levels of MAC-2 expression and extent of phagocytosis over a wide range of values obtained from $\mathrm{N}$ and $\mathrm{W}$ mouse nerves. Increasing levels of $\mathrm{MAC}-2$ production were accompanied by extended destruction of myelin by phagocytosis.

An interesting feature in $\mathrm{W}$ mice is the fact that nerve injury induced W mouse Schwann cells to express the galactose-specific lectin MAC-2 in vitro but not in vivo at locations farther distal than $3 \mathrm{~mm}$ from sites of nerve transection. In marked contrast, $\mathrm{N}$ mouse Schwann cells expressed MAC- 2 during in vivo as well as during in vitro nerve degeneration. Thus, W and N Schwann cells differ in their in vivo response to nerve transection. In vitro, the response is qualitatively similar but quantitatively different, as W mouse Schwann cells expressed less MAC-2 than N mouse Schwann cells did. An observation similar in nature was made with regard to the expression of mRNA coding for the major myelin protein Po (Thomson et al., 1991). A characteristic feature in Wallerian degeneration is the downregulation of Po mRNA levels by Schwann cells. W mouse Schwann cells did not do so after nerve transection in vivo but did so in culture. Thus, in W mice some of the characteristic responses of Schwann cells to nerve transection are suppressed in vivo but are displayed in vitro. These observations suggest the possibility of the existence of an inhibitory humoral factor in $\mathrm{W}$ mice. The quantitative differences in MAC-2 expression between $\mathrm{N}$ and $\mathrm{W}$ nerve explants further suggest that alleviation of a suppressive factor is most probably not the only element governing the response of W mouse Schwann cells, and possibly also other non-neuronal cells, to axotomy.

\section{References}

Aamar S, Saada A, Rotshenker S (1992) Lesion-induced changes in the production of newly synthesized and secreted Apo-E and other molecules are independent on the concomitant recruitment of blood born macrophages into injured peripheral nerve. J Neurochem 59: $1287-1292$.

Austin JM, Gordon S (1981) F4/80; a monoclonal antibody directed specifically against the mouse macrophage. Eur J Immunol 10:805811.

Bedi KS, Winter J, Berry M, Cohen J (1992) Adult rat dorsal root neurons extend neurites on predegenerated but not normal peripheral nerves in vitro. Eur J Neurosci 4:193-200.

Beuche W, Friede RL (1984) The role of non-resident cells in Wallerian degeneration. J Neurocytol 13:767-796.

Bigbee JW, Yoshino JE, DeVries GII (1987) Morphological and proliferative responses of cultured Schwann cells following rapid phagocytosis of a myelin-enriched fraction. J Neurocytol 16:487-496.

Cherayil BJ, Weiner SJ, Pillai S (1989) The MAC-2 antigen is a galactose-specific lectin that binds IgE. J Exp Med 170:1959-1972.

Cherayil BJ, Chaitovitz S, Wong C, Pillai S (1990) Molecular cloning of a human macrophage lectin specific for galactose. Proc Natl Acad Sci USA 87:7324-7328. 
Crang AJ, Blakemore WF (1986) Observations on Wallerian degeneration in explant cultures of cat sciatic nerve. J Neurocytol 15:471482.

David S, Aguayo AJ (1981) Axonal elongation into peripheral nervous system bridges after central nervous system injury in adult rats. Science 214:931-933.

Frigeri LC, Robertson MW, Liu FT (1990) Expression of biologically active recombinant rat IgE-binding protein in Escherichia coli. J Biol Chem 265:20763-20769.

Hann Bonnekooh P, Schmidt P, Friede RL (1989) Myelin phagocytosis by peritoneal macrophages in organ cultures of mouse peripheral nerve. A new model for studying myelin phagocytosis in vitro. $\mathbf{J}$ Neuropathol Exp Neurol 48:140-153.

Heumann R, Korsching S, Bandtlow C, Thoenen H (1987) Changes in nerve growth factor synthesis in nonneuronal cells in response to sciatic nerve transection. J Cell Biol 104:1623-1631.

Ho MK, Springer TA (1982) Mac-2, a novel 32,000 $M$, mouse macrophage subpopulation-specific antigen defined by monoclonal antibodies. J Immunol 128:1221-1227.

Ide C, Tohyama K, Yokota R, Nitatori T, Onodera S (1983) Schwann cell basal lamina and nerve regeneration. Brain Res 288:61-75.

Ignatius MJ, Gebicke-Harter PJ, Pitas RE, Shooter EM (1986) Expression of apolipoprotein $\mathrm{E}$ in nerve injury and repair. Prog Brain Res 71:177-184.

Jia S, Wang JL (1988) Carbohydrate binding protein 35. Complementary DNA sequence reveals homology with proteins of the heterogeneous nuclear RNP. J Biol Chem 13:6009-6011.

Leenen PJM, Jansen AMAC, van Ewijk W (1986) Murine macrophages can be ordered in a linear differentiation sequence. Differentiation 32:1.57-164.

Liu FT, Albrandt K, Mendel E, Kulczycki A Jr, Orida NO (1985) Identification of an IgE-binding protein by molecular cloning. Proc Natl Acad Sci USA 82:4100-4104.

Lunn ER, Perry VH, Brown MC, Rosen H, Gordon S (1989) Absence of Wallerian degeneration does not hinder regeneration in peripheral nerve. Eur J Neurosci 1:27-33.

McLean IW, Nakane PK (1974) Periodate-lysine-paraformaldehyde fixative a new fixative for immunoelectron microscopy. J Histochem Cytochem 22:1077-1083.

Morrissey TK, Kleitman N, Bunge P (1991) Isolation and functional characterization of Schwann cells derived from adult peripheral nerve. J Neurosci 11:2433-2442.

Moutsatsos KJ, Wade M, Schindler M, Wang JL (1987) Endogenous lectins from cultured cells: nuclear localization of carbohydrate binding protein 35 in proliferating 3 T3 fibroblasts. Proc Natl Acad Sci USA 84:6452-6456.

Nibbering PH, Leijh PCJ, van-Furth R (1987) Quantitative immunocytochemical characterization of mononuclear phagocytes. II Monocytes and tissue macrophages. Immunology 62:171-176.

Ofek I, Sharon N (1988) Lectinophagocytosis: a molecular mechanism of recognition between cell surface sugars and lectins in the phagocytosis of bacteria. Infect Immunol 56:539-547.

Oulton MR, Mezei C (1976) Characterization of myelin of chick sciatic nerve during development. J Lipid Res 17:167-175.

Papadimitriou JM, Ashman RB (1989) Macrophages: current views on their differentiation, structure and function. Ultrastruct Pathol 13: 343-372.

Perry VH, Brown MC, Lunn ER, Tree P, Gordon S (1990) Evidence that very slow Wallerian degeneration in C57BL/Ola mice is intrinsic property of the peripheral nerve. Eur J Neurosci 2:802-808.

Ramon y Cajal S (1928) Degeneration and regeneration of the nervous system. Reprint. New York: Hafner, 1968

Raz A, Pazerini G, Carmi P (1989) Identification of the matastasisassociated, galactoside-binding lectin as a chimeric gene product with homology to an IgE-binding protein. Cancer Res 49:3489 3493.

Raz A, Carmi P, Raz T, Hogan V, Mohamed A, Wolman SR (1991) Molecular cloning and chromosomal mapping of a human galactoside-binding protein. Cancer Res 51:2173-2178.

Richardson PM, Ebendal T (1982) Nerve growth activities in rat peripheral nerve. Brain Res 246:57-64.

Rotshenker S, Reichert F, Shooter EM (1990) Lesion induced synthesis and secretion of proteins by nonneuronal cells resident in frog peripheral nerve. Proc Natl Acad Sci USA 87:1144-1148.

Rotshenker S, Aamar S, Barak V (1992) Interleukine-1 activity in injured peripheral nerve. J Neuroimmunol 39:75-80.

Scarpini E, Kreider BQ, Lisak RP, Pleasure DE (1988) Establishment of Schwann cell cultures from adult rat peripheral nerve. Exp Neurol 102:167-176.

Schubert, T, Friede RL (1981) The role of endoneurial fibroblasts in myelin degradation. J Neuropathol Exp Neurol 40:134-154.

Stefansson K, Wollman RL, Moore BW (1982) Distribution of S-100 protein outside the central nervous system. Brain Res 234:309-317.

Stoll G, Griffin JW, Li CY, Trapp BD (1989) Wallerian degeneration in the peripheral nervous system: participation of both Schwann cells and macrophages in myelin degradation. J Neurocytol 18:671-683.

Thomas PK (1963) The connective tissue of peripheral nerve: an electron microscope study. J Anat 97:35-44.

Thomson CE, Mitchel LS, Griffiths IR, Morrison S (1991) Retarded Wallerian degeneration following peripheral nerve transection in C57BL/6/Ola mice is associated with delayed down regulation of the Po gene. Brain Res 538:157-160.

van-Furth $R$ (1988) Phagocytic cells: development and distribution of mononuclear phagocytes in normal steady state and inflammation. In: Inflammation. Basic principles and clinical correlates. pp 281295. New York: Raven.

Woo HJ, Shaw ML, Messier JM, Mercurio MA (1990) The major non-integrin laminin binding protein of macrophages is identical to carbohydrate binding protein 35 (MAC-2). J Biol Chem 265:70977099. 